\title{
Green synthesis of lignin nano- and micro-particles: Physicochemical characterization, bioactive properties and cytotoxicity assessment
}

\author{
Filipa M.C. Freitas ${ }^{\mathrm{a}}$, Miguel A. Cerqueira ${ }^{\mathrm{b}}$, Catarina Gonçalves ${ }^{\mathrm{b}}$, Sarah Azinheiro ${ }^{\mathrm{b}}$, Alejandro Garrido-Maestu ${ }^{\mathrm{b}}$, \\ António A. Vicente ${ }^{a}$, Lorenzo M. Pastrana ${ }^{b}$, José A. Teixeira ${ }^{a}$, Michele Michelin ${ }^{\mathrm{a}, *}$ \\ a Centre of Biological Engineering, University of Minho, Campus de Gualtar, 4710-057 Braga, Portugal \\ b International Iberian Nanotechnology Laboratory, Av. Mestre José Veiga, 4715-330 Braga, Portugal
}

\section{A R T I C L E I N F O}

\section{Article history:}

Received 8 July 2020

Received in revised form 13 September 2020

Accepted 15 September 2020

Available online 19 September 2020

\section{Keywords:}

Lignocellulose

Nanotechnology

Antioxidant

Biocompatibility

Cytotoxicity

\begin{abstract}
A B S T R A C T
Lignin particles (LPs) have gained prominence due to their biodegradability and bioactive properties. LP production at nano and micro scale produced from organosolv lignin and the understanding of size's effect on their properties is unexplored. This work aimed to produce and characterize lignin nanoparticles and microparticles using a green synthesis process, based on ethanol-solubilized lignin and water. Spherical shape LPs, with a mean size of $75 \mathrm{~nm}$ and $215 \mathrm{~nm}$ and with a low polydispersity were produced, as confirmed by transmission electron microscopy and dynamic light scattering. LPs thermal stability improved over raw lignin, and the chemical structure of lignin was not affected by the production method. The antimicrobial tests proved that LPs presented a bacteriostatic effect on Escherichiacoli and Salmonella enterica. Regarding the antioxidant potential, LPs had a good antioxidant activity that increased with the reaction time and LPs concentration. LPs also presented an antioxidant effect against intracellular ROS, reducing the intracellular ROS levels significantly. Furthermore, the LPs showed a low cytotoxic effect in Caco-2 cell line. These results showed that LPs at different scales (nano and micro) present biological properties and are safe to be used in different high value industrial sectors, such as biomedical, pharmaceutical and food.
\end{abstract}

(c) 2020 Elsevier B.V. All rights reserved.

\section{Introduction}

Lignin is a natural aromatic biopolymer and a renewable resource obtained from lignocellulosic biomass, representing $10-15 \%$ of these materials [1]. Currently, it has been used as additive, binder, dispersant,

\footnotetext{
Abbreviations: ABTS, 2,2'-azino-bis (3 ethylbenzothiazoline-6-sulphonic acid); ATCC, American type culture collection; BHA, butylated hydroxyanisole; BHT, butylated hydroxytoluene; $\mathrm{CH}$, chitosan; $\mathrm{CFU}$, colony-forming unit; $\mathrm{CO}_{2}$, carbon dioxide; DCF, dichlorofluorescein; DCFH-DA, 2'7'-dichorodihydrofluorescein diacetate; DLS, dynamic light scattering; DSC, differential scanning calorimetry; DTG, derivative thermogravimetry; EC, European commission; EDTA, ethylenediaminetetraacetic acid; FBS, fetal bovine serum; FDA, food and drug administration; FTIR, Fourier transform infrared spectroscopy; $\mathrm{G}$, guaiacyl; $\mathrm{H}$, p-hydroxyl phenyl; $\mathrm{H}_{2} \mathrm{O}_{2}$, hydrogen peroxide; $\mathrm{IC}_{50}$, half maximal inhibitory concentration; HBSS, Hank's balanced salt solution; LB, LuriaBertani; LMPs, lignin microparticles; LNPs, lignin nanoparticles; LPs, lignin particles; MEM, minimum essential media; MTT, 3-(4,5-dimethylthiazol-2-yl)-2,5-diphenyltetrazolium bromide; NEAA, non-essential amino-acids; NM, nanomaterial; NPs, nanoparticles; OD, optical density; OL, organosolv lignin; PBS, phosphate-buffered saline; PDI, polydispersity index; PVA, polyvinyl alcohol; ROS, reactive oxygen species; RSA, radical scavenging activity; S, syringyl; TEM, transmission electron microscopy; TG, thermogravimetric curve; $T_{g}$, glass transition temperature; TGA, thermogravimetric analyzer; THF, tetrahydrofuran; Trolox, 6-hydroxy-2,5,7,8-tetramethylchroman-2-carboxylic acid; TSA, tryptic soy agar; UV, ultraviolet.

* Corresponding author.

E-mail address: mimichelin@ceb.uminho.pt (M. Michelin).
}

adsorbent or surfactant $[2,3]$. However, the very limited solubility of the native material and the complexity of the lignin structure with very broad molecular weight distributions and a random microstructure have limited its use [4]. The functional groups, both phenolic and aliphatic hydroxyls, make it susceptible to chemical modification or polymerization, enabling the development of new materials [5-7]. Besides that, lignin presents some eco-friendly properties, such as biodegradability, biocompatibility and low toxicity, which make it an ideal precursor for the development of LNPs [8].

Nowadays, the development of NPs from lignin has gained interest, given its nature, for drug delivery systems [9-11], delivery of hydrophobic molecules [12], improvement of UV barrier [13,14], as reinforcing agent in nanocomposites [15], sorbents for heavy metal ions and other environmental pollutants, and antibacterial and antioxidant applications [16-19]. They have also been used as an alternative to inorganic NPs due to some safety issues raised in recent years [8]. Thus, different sources of lignin have been used, being most works focused on alkali and kraft lignin [2,8,9,20-23]. For instance, Frangville et al. [8] produced nanosized lignin particles through acid precipitation using ethylene glycol as a solvent and kraft lignin. Qian et al. [2] and Lievonen et al. [21] prepared spherical NPs from acetylated alkali lignin and kraft lignin, respectively, using THF as a solvent and the solvent displacement method. Myint et al. [24] produced LNPs using kraft lignin through compressed 
$\mathrm{CO}_{2}$ antisolvent method. LPs based on organosolv lignin were produced by Richter et al. [25] and Liu et al. [26], using acetone and tetrahydrofuran as a solvent, respectively, through the solvent displacement method. Most of these published production methods have some drawbacks, including extensive use of organic solvents that poses a potential hazard to the environment, irregular shapes and difficulty to control the particle size and size distribution.

In the current work, lignin particles were produced from organosolv lignin, using ethanol as solvent through the solvent displacement method by dripping the lignin solution in an antisolvent (water). Matsakas et al. [27,28] also reported the production of LNPs from organosolv lignin solubilized in ethanol by the solvent displacement method through the solvent evaporation or by adding an antisolvent via dialysis or dilution. This approach is interesting since it avoid some of the drawbacks described above, such as toxic and expensive solvents and particles with irregular shapes. Ethanol is considered a green, safer and cost-effective solvent and is completely miscible with water.

In 2011, the EC adopted a new definition for nanomaterial [29], referred in this work as 'EC NM definition', which refers 'Nanomaterial' as a natural, incidental or manufactured material containing particles, in an unbound state or as an aggregate or agglomerate, where $50 \%$ or more particles (number size distribution) have one or more external dimensions in the size range of $1 \mathrm{~nm}-100 \mathrm{~nm}$. In specific cases and where warranted by concerns for the environment, health, safety or competitiveness the number size distribution threshold of $50 \%$ may be replaced by a threshold between 1 and 50\%. By other side, the FDA mentions that in some cases material with sizes up to $1000 \mathrm{~nm}$ should also be considered nanomaterial, justified by the fact "at the present time, available scientific information does not establish a uniform upper boundary above $100 \mathrm{~nm}$ where novel properties and phenomena similar to those seen in materials with dimensions in the nanoscale range cease for all potential materials or end products" [30]. Based on this, materials with sizes higher than $100 \mathrm{~nm}$ should be evaluated in terms of their properties and safety, such as micro and nanostructures based on biomacromolecules, that due to their complexity should be evaluated case-by-case. In the case of lignin, this has never been addressed and the advantages and challenges of using lignin as a nanomaterial when compared with micro size are not fully understood.

Thus, this study reports the production of lignin particles (LPs) with different size scales (nano and micro), according to the EC NM definition, using a green synthesis process and correlates their main properties, including the possible cytotoxicity. LPs were characterized by dynamic light scattering and transmission electron microscopy. Their chemical structure and thermal stability were evaluated by FTIR, TGA and DSC. Moreover, bioactive properties of LPs were evaluated through antioxidant and antimicrobial tests. Finally, the in vitro cytotoxicity and the cellular antioxidant activity of LPs were assessed using a Caco-2 cell line.

\section{Materials and methods}

\subsection{Materials}

Organosolv lignin (OL) of high purity $(98.73 \pm 0.36 \%)$ was extracted from corncob through two sequential pretreatments, involving liquid hot water at $200{ }^{\circ} \mathrm{C}$ for $30 \mathrm{~min}$ and organosolv at $140{ }^{\circ} \mathrm{C}$ for $40 \mathrm{~min}$, using $60 \%(\mathrm{v} / \mathrm{v})$ ethanol solution, according to Michelin el al. [31]. Ethanol was obtained from Panreac Química SLU (Spain). The chemicals ABTS, Trolox, BHT and BHA, ascorbic acid and gallic acid were purchased from Sigma-Aldrich. MEM and PBS $10 \times$ were purchased from Thermo Fisher Scientific (Waltham, MA, USA). Trypsin-EDTA (0.25\% trypsin$0.1 \%$ EDTA), penicillin/streptomycin 100×, FBS, NEAA and HBSS were purchased from Merck Millipore (Burlington, MA, USA). Sodium pyruvate solution $100 \mathrm{mM}$, resazurin sodium salt and thiazolyl blue tetrazolium bromide, DCFH-DA and $\mathrm{H}_{2} \mathrm{O}_{2}$ solution $30 \%(\mathrm{w} / \mathrm{w}$ ) were obtained from Sigma-Aldrich (St. Louis, MO, USA). Isopropanol was purchased from Riedel-de-Haen.

\subsection{Production of lignin particles}

LPs were produced according to Fessi et al. [32] using the solvent displacement method. Three parameters were evaluated in the LPs production: flow rate $\left(\mathrm{mL} \cdot \mathrm{min}^{-1}\right)$, lignin concentration $\left(\mathrm{mg} \cdot \mathrm{mL}^{-1}\right)$ and ethanol/water ratio. Initially, different concentrations of the crude lignin were solubilized into ethanol (100\%). From this organic phase, LPs were produced by dripping it at a controlled flow rate into distilled water (aqueous phase) up to a final volume of $50 \mathrm{~mL}$ and constant stirring of $300 \mathrm{rpm}$. The drip of the organic phase was done dropwise with a polypropylene syringe of $10 \mathrm{~mL}$ and a needle of $0.60 \times 25 \mathrm{~mm}$, using a syringe pump (NE-1000 Multiphaser ${ }^{\mathrm{TM}}$ Programmable Syringe Pump, New Era Pump Systems Inc.) to control the drip rate. The organic solvent was completely removed by vacuum evaporation at a constant temperature of $40{ }^{\circ} \mathrm{C}$ to recover the LPs. The experimental conditions (5.82 $\mathrm{mg} \cdot \mathrm{mL}^{-1}$ lignin and 0.071 ethanol/water ratio, and $14.18 \mathrm{mg} \cdot \mathrm{mL}^{-1}$ lignin and 0.305 ethanol/water ratio, at a flow rate of $0.17 \mathrm{~mL} \cdot \mathrm{min}^{-1}$ for both conditions) were chosen in order to obtain LPs around $100 \mathrm{~nm}$ (LNPs) and $300 \mathrm{~nm}$ (LMPs), respectively (data not shown). The water dispersed LPs obtained from this process were also freeze dried (CHRIST - Alpha 1-4 LD plus, Germany) to obtain dried LPs.

\subsection{Dynamic light scattering}

LPs were characterized for their mean size, PDI and zeta potential through DLS using a Malvern Zetasizer Nano ZS instrument [33]. To determine the size and PDI, $14 \mathrm{~mm}$ square polystyrene cuvettes (DTS0014) were used, while for the zeta potential, disposable capillary cell (DTS1070) was used. All measurements were performed at $25^{\circ} \mathrm{C}$. Each measurement of size distribution (by intensity and number) and PDI were performed with a detection angle of $173^{\circ}$ and zeta potential measurements with an angle of $17^{\circ}$, and the zeta potential values were calculated using Smoluchowski's model. Measurements were performed at least three times.

\subsection{Transmission electron microscopy}

The surface morphology of the LPs was evaluated through a TEM JEM-2100 (JEOL, Japan) operated at a $200 \mathrm{kV}$ accelerating voltage. Before loading the samples into the microscope (direct deposition), the samples were drop-cast onto a carbon coated copper grid (Lacey carbon support film, 400 mesh, Copper, Ted Pella Inc., USA), and dried at room temperature.

\subsection{Attenuated total reflectance Fourier transform infrared spectroscopy}

The chemical structure of lignin and LPs was evaluated by ATR-FTIR. The ATR-FTIR spectra were recorded on a spectrophotometer model Alpha II (Bruker, Germany) of direct transmittance on the dried solid samples. Dried samples were analyzed from 4000 to $500 \mathrm{~cm}^{-1}$ at a resolution of $4 \mathrm{~cm}^{-1}$ and 16 scans were recorded. Analyses were performed in triplicate.

\subsection{Thermal analysis}

Thermo degradation of lignin and LPs was carried out under a nitrogen atmosphere of $20 \mathrm{~mL} \cdot \mathrm{min}^{-1}$, using a TGA 4000 (Perkin Elmer, Instrumentos de Laboratório e Científicos, Lda, Portugal). Approximately, $10 \mathrm{mg}$ of dried sample was loaded into a ceramic pan. TG analyses were conducted in a temperature range from $20^{\circ} \mathrm{C}$ to $800{ }^{\circ} \mathrm{C}$, at a heating rate of $10^{\circ} \mathrm{C} \cdot \mathrm{min}^{-1}$, in duplicate. $T_{g}$ of lignin and LPs was performed in a DSC analyzer 6000 (Perkin Elmer, Instrumentos de Laboratório e Científicos, Lda, Portugal). Approximately $5 \mathrm{mg}$ of dried 
sample was placed into a hermetic and sealed pan. The samples were first heated from $0{ }^{\circ} \mathrm{C}$ to $120^{\circ} \mathrm{C}$ at a rate of $10^{\circ} \mathrm{C} \cdot \mathrm{min}^{-1}$, then cooled to $0{ }^{\circ} \mathrm{C}$ at a rate of $10{ }^{\circ} \mathrm{C} \cdot \mathrm{min}^{-1}$, and finally heated from $0{ }^{\circ} \mathrm{C}$ to $200{ }^{\circ} \mathrm{C}$ at a rate of $10^{\circ} \mathrm{C} \cdot \mathrm{min}^{-1}$ under nitrogen atmosphere of $20 \mathrm{~mL} \cdot \mathrm{min}^{-1}$. $T_{g}$ of each sample was determined with the second heating scanning. Analyses were performed in triplicate.

\subsection{Antioxidant activity}

Lignin and LPs antioxidant capacity was studied by evaluating free RSA through ABTS. The RSA was performed according to the method of Re et al. [34], which is based on the ability of antioxidants to neutralize the ABTS radical, decreasing its absorbance at $734 \mathrm{~nm}$. Commercial antioxidants such as Trolox, BHT, BHA, ascorbic acid and gallic acid, as well as raw lignin were used as references. Firstly, ABTS solution was prepared by mixing $7 \mathrm{mM}$ ABTS ammonium with $2.45 \mathrm{mM}$ potassium persulfate, and then incubated at room temperature for $12-16 \mathrm{~h}$ in the dark. After that, ABTS solution was diluted with Milli-Q water to get an absorbance of $0.70 \pm 0.02$ at $734 \mathrm{~nm}$. Then, $100 \mu \mathrm{L}$ of ABTS solution was added to $100 \mu \mathrm{L}$ of antioxidant sample (LPs were dispersed in water, while the reference antioxidants, including lignin, were dispersed in $60 \%(\mathrm{v} / \mathrm{v})$ of ethanol), at concentrations between 0.005 and $0.1 \mathrm{mg} \cdot \mathrm{mL}^{-1}$. After $6 \mathrm{~min}$, the percentage of inhibition at $734 \mathrm{~nm}$ was calculated for each concentration relative to the control absorbance. The percentage of RSA was calculated using the equation:

$\operatorname{RSA}(\%)=\left[\left(\frac{\mathrm{A}_{\text {control }}-\mathrm{A}_{\text {sample })}}{\mathrm{A}_{\text {control }}}\right] \times 100\right.$

where $A_{\text {control }}$ is the absorbance of the control sample and $A_{\text {sample }}$ is the absorbance of the commercial antioxidants, lignin or LPs samples.

The $\mathrm{IC}_{50}$ value was calculated as the concentration of the compounds that causes $50 \%$ reduction in the ABTS. All experiments were carried out in triplicate.

\subsection{Antimicrobial activity}

The antimicrobial activity of LPs was tested against Escherichia coli 0157:H7 (WDCM 00014) and Salmonella enterica serovar Typhimurium (WDCM 00031). The culture turbidity as a qualitative measure of cell growth was performed in 96-wells plates. A fresh colony of each strain, maintained on TSA medium at $4{ }^{\circ} \mathrm{C}$, was picked up and suspended evenly in separate glass tubes containing $4 \mathrm{~mL}$ LB medium. The tubes were incubated aerobically at $37^{\circ} \mathrm{C}$ for $24 \mathrm{~h}$. LPs were added into each well with $\mathrm{LB}$ medium at a final concentration of $1 \mathrm{mg} \cdot \mathrm{mL}^{-1}$. Each well was inoculated with $2 \mu \mathrm{L}$ of an overnight culture diluted to a final concentration of approximately $10^{2} \mathrm{CFU} \cdot \mathrm{mL}^{-1}$ (total well volume of $200 \mu \mathrm{L}$ ). Following inoculation, the OD at $600 \mathrm{~nm}$ of the cultures was monitored every half hour during $24 \mathrm{~h}$ (under constant stirring) using a Microplate Reader (Synergy, BioteK H 1, USA). As a positive control, culture medium containing only bacteria without LPs was used. To avoid potential optical interference during measurements of the growing cultures caused by the light-scattering properties of the LPs, the same liquid medium without microorganisms, but containing the same concentration of NPs was cultured under the same conditions as blank controls. The growth rate of microbial cells interacting with the LPs was determined from a plot of the optical density at $600 \mathrm{~nm}$ versus time. All measurements were performed in triplicate. The data obtained were analyzed with the mathematical model presented by GarridoMaestu et al. [35]. From this model, the maximal growth, the duration of the lag phase and the slope of the curve were calculated to evaluate the effect of the LPs in the bacteria.

\subsection{Cell culture}

Caco- 2 cells, clone HTB-37 $7^{\mathrm{TM}}$, from human colon carcinoma, were obtained from the ATCC $®$. Caco-2 cells (passage 25-40) were cultured in MEM, supplemented with $20 \%$ FBS, $1 \%$ NEAA, $1 \%$ sodium pyruvate and $1 \%$ penicillin/streptomycin. The cells were kept at $37{ }^{\circ} \mathrm{C}$ and $5 \%$ $\mathrm{CO}_{2}$ in $75 \mathrm{~cm}^{2}$ flasks. For the in vitro assays, confluent cells were detached using $0.25 \%$ trypsin-EDTA solution, then precipitated by centrifugation at $1080 \mathrm{rpm}$ for $5 \mathrm{~min}$ and resuspended in fresh MEM at a concentration of $1 \times 10^{5}$ cells $\cdot \mathrm{mL}^{-1}$. Cells were seeded onto 96-wells plates at a density of $1 \times 10^{4}$ cells ( $100 \mu \mathrm{L}$ of cellular suspension) per well and left adhering overnight in a humidified atmosphere of 5\% $\mathrm{CO}_{2}$ in air at $37^{\circ} \mathrm{C}$.

\subsection{Cytotoxicity}

The cytotoxicity of LPs was determined indirectly by resazurin or MTT assays. After adhesion, the culture medium was removed and replaced by $200 \mu \mathrm{L}$ of samples: LNPs or LMPs diluted $(10 \%, v / v)$ in the culture medium and incubated for 4 or $24 \mathrm{~h}$. LNPs or LMPs were prepared in distilled water and tested at different final concentrations: 0.005 , $0.01,0.05,0.1$ or $0.2 \mathrm{mg} \cdot \mathrm{mL}^{-1}$. A negative control was performed using cells growing in MEM with $10 \%(\mathrm{v} / \mathrm{v})$ of distilled water (considered as $100 \%$ cell viability).

Resazurin assay: At each time-point ( 4 or $24 \mathrm{~h}$ ), $20 \mu \mathrm{L}$ of resazurin solution $\left(0.1 \mathrm{mg} \cdot \mathrm{mL}^{-1}\right.$ in PBS) were added to each well (final concentration $\left.0.01 \mathrm{mg} \cdot \mathrm{mL}^{-1}\right)$. The fluorescence intensity that is proportional to the number of viable cells was measured, after $5 \mathrm{~h}$ of incubation, using a Microplate Fluorescence Reader (Synergy, BioteK H 1, USA) at an excitation wavelength of $560 \mathrm{~nm}$ and an emission wavelength of $590 \mathrm{~nm}$. The \% cell viability was expressed as fluorescence of treated cells compared to the fluorescence of cells growing in the culture medium as follows:

$\%$ cell viability $=\left[\frac{\left(F_{T C}-F_{S}\right)}{\left(F_{C}-F_{C M}\right)}\right] \times 100$

where $\mathrm{F}_{\mathrm{TC}}$ is the fluorescence of treated cells, $\mathrm{F}_{\mathrm{S}}$ is the fluorescence of sample in the culture medium (without cells), $\mathrm{F}_{\mathrm{C}}$ is the fluorescence of cells growing in the culture medium with $10 \%(\mathrm{v} / \mathrm{v})$ of distilled water (considered as $100 \%$ cell viability), $\mathrm{F}_{\mathrm{CM}}$ is the fluorescence of culture medium with $10 \%(\mathrm{v} / \mathrm{v})$ of distilled water (without cells).

MTT assay: After the incubation time, samples were removed and $100 \mu \mathrm{L}$ of MTT solution $\left(1.0 \mathrm{mg} \cdot \mathrm{mL}^{-1}\right.$ in distilled water) were added to each well and incubated at $37^{\circ} \mathrm{C}$. After $3 \mathrm{~h}$, MTT solution was removed and MTT-formazan crystals were dissolved with $100 \mu \mathrm{L}$ isopropanol. Absorbance was measured at $570 \mathrm{~nm}$ and $690 \mathrm{~nm}$ (reference wavelength) using a Microplate Reader (Synergy, BioteK H1, USA). The cell viability was expressed in percentage of absorbance in treated cells in relation to the absorbance of cells growing in MEM with $10 \%(\mathrm{v} / \mathrm{v})$ of distilled water.

\subsection{Cellular antioxidant activity}

In vitro assays are widely used to evaluate the antioxidant potential of compounds, however they cannot accurately predict antioxidant behavior in living systems. Thus, cell-based assays are gaining importance as they provide a biological perspective. Caco- 2 cells have been used to assess the effectiveness of dietary antioxidants since they are of similar morphology, enzymes, microvillar structure, tight junction and permeability as small intestinal epithelial cells [36]. The generation of intracellular ROS was evaluated by using oxidation sensitive DCFH-DA. The DCFH-DA is a non-fluorescent cell permeant reagent that measures hydroxyl, peroxyl and other ROS activity within the cell. After diffusion into the cell, DCFH-DA is deacetylated by cellular esterases to a nonfluorescent compound, which is later oxidized by ROS into DCF allowing 
the assessment of ROS activity. When ROS production is not compensated by the cellular antioxidant defense system, oxidative stress occurs [37]. Bioactive compounds can quench this reaction and prevent the generation of DCF. This can be accomplished on the cell membrane surface or within the cell following uptake of the antioxidant compounds [38].

After cell adhesion, the culture medium was removed and $100 \mu \mathrm{L}$ of $10 \mu \mathrm{M}$ DCFH-DA solution was added to each well and incubated for $1 \mathrm{~h}$ at $37{ }^{\circ} \mathrm{C}$. Afterwards, the reagent was removed and $100 \mu \mathrm{L}$ of LNPs or LMPs, in HBSS, were added to each well, at a final concentration of $0.005,0.01,0.05$ or $0.1 \mathrm{mg} \cdot \mathrm{mL}^{-1}$, and incubated for 4 or $24 \mathrm{~h}$. At each time point, the fluorescence intensity was measured using a Microplate Fluorescence Reader (Synergy, BioteK H1, USA) at an excitation wavelength of $495 \mathrm{~nm}$ and an emission wavelength of $525 \mathrm{~nm}$. The intracellular ROS was expressed in percentage of fluorescence of cells treated with samples in relation to the fluorescence of cells treated with $0.25 \mathrm{mM} \mathrm{H}_{2} \mathrm{O}_{2}$, as a positive control.

In order to investigate the protective effect of LNPs or LMPs, $0.25 \mathrm{mM}$ $\mathrm{H}_{2} \mathrm{O}_{2}$-stimulated Caco-2 cells [39] were exposed to different particles' concentrations $\left(0.005,0.01,0.05\right.$ or $\left.0.1 \mathrm{mg} \cdot \mathrm{mL}^{-1}\right) .1 \times 10^{4}$ cells ( $100 \mu \mathrm{L}$ of cellular suspension) were seeded in 96-wells plates and left adhering overnight in a humidified atmosphere of $5 \% \mathrm{CO}_{2}$ in air at $37^{\circ} \mathrm{C}$. Then, the medium was removed and $100 \mu \mathrm{L}$ of $10 \mu \mathrm{M}$ DCFH-DA solution was added to each well and incubated for $1 \mathrm{~h}$ at $37^{\circ} \mathrm{C}$. Afterwards, DCFH-DA solution was removed and $100 \mu \mathrm{L}$ of LPs, in HBSS, were added to each well, at a final concentration of 0.005, 0.01, 0.05 or $0.1 \mathrm{mg} \cdot \mathrm{mL}^{-1}$, and incubated for 4 or $24 \mathrm{~h}$. After each time point, LPs were removed, cells were washed with $100 \mu \mathrm{L}$ of PBS and exposed to $100 \mu \mathrm{L}$ of $0.25 \mathrm{mM} \mathrm{H}_{2} \mathrm{O}_{2}$ for $1 \mathrm{~h}$ to induce oxidative stress. The fluorescence intensity was measured using a Microplate Fluorescence Reader (Synergy, BioteK H1, USA) at an excitation wavelength of $495 \mathrm{~nm}$ and an emission wavelength of $525 \mathrm{~nm}$. The intracellular ROS was expressed in percentage of fluorescence of cells treated with LPs in relation to the fluorescence of cells treated with HBSS after stimulation with $0.25 \mathrm{mM}$ $\mathrm{H}_{2} \mathrm{O}_{2}$.

\subsection{Statistical analysis}

Data analyses were performed using Microsoft Excel 2016. All data were reported as mean standard deviation (sd) from at least three values. Statistical analyses were performed using GraphPad Prism software (version 8.3.0). Results were subjected to analysis of variance (two-way ANOVA) and the differences between means were calculated using Holm-Sidak or Tukey's multiple comparison tests. They were considered significant when $\mathrm{p}$-values were below $0.05(\mathrm{p}<0.05)$.

\section{Results and discussion}

\subsection{Size, polydispersity index and zeta potential of LPS}

The size, PDI and zeta potential are essential parameters to evaluate the stability and homogeneity of particles in solution, and were considered, in this case, the most important parameters during the production of LPs. In order to obtain particles with the desired characteristics, such as lower PDI and defined size, two production conditions were chosen: one with the lowest concentration of lignin and ethanol and another with the highest concentration of lignin and ethanol, since these were the two variables influencing the size of LPs (results not shown). The flow rate was kept low, for both conditions, in order to obtain low PDI values. In this way, the LPs production conditions were: i) $5.82 \mathrm{mg} \cdot \mathrm{mL}^{-1}$ lignin, 0.071 ethanol $/$ water ratio and $0.17 \mathrm{~mL} \cdot \mathrm{min}^{-1}$ flow rate in order to obtain LNPs around $100 \mathrm{~nm}$; and ii) $14.18 \mathrm{mg} \cdot \mathrm{mL}^{-1}$ of lignin, 0.305 ethanol/water ratio and a flow rate of $0.17 \mathrm{~mL} \cdot \mathrm{min}^{-1}$ to obtain LMPs around $300 \mathrm{~nm}$. The water dispersed LPs produced in these conditions were characterized by measuring the size (by intensity and number), PDI and zeta potential values
(Table 1). The LPs presented different size depending on whether they are presented by the intensity or by the number distribution, being in both cases the particle size by intensity higher than by number. Different factors can explain the difference between these measurements as explained elsewhere [40] and therefore the sizes were confirmed by TEM. TEM (see Section 3.2 Morphology of LPs) confirmed the mean sizes by number, $75.74 \mathrm{~nm}$ (149.22 nm by intensity) and $215 \mathrm{~nm}$ ( $323.67 \mathrm{~nm}$ ) (215 nm by intensity) for the LPs produced, and therefore they were named lignin nanoparticles (LNPs) and lignin microparticles (LMPs), respectively. This denomination was based on the number distribution once LNPs presented around 95\% of NPs with sizes $\leq 100 \mathrm{~nm}$, fitting in the nanomaterial definition according to EC regulation. On the other, hand, LMPs presented less than $5 \%$ of particles with size $\leq$ $100 \mathrm{~nm}$, and then they were considered microparticles. The larger size of LMPs, relative to LNPs, can be explained by the high concentration of lignin and ethanol used for LMPs production. Due to the high concentration of lignin, more lignin macromolecules participate in the formation of each particle, resulting in larger diameter particles [14].

Similar behavior was observed by other authors that also observed that the lignin particles size increased with an increase of the lignin's concentration. Liu et al. [26] produced LPs with sizes ranging from $52.6 \mathrm{~nm}$ to $210.8 \mathrm{~nm}$, when the lignin concentration was increased from $5 \mathrm{mg} \cdot \mathrm{mL}^{-1}$ to $20 \mathrm{mg} \cdot \mathrm{mL}^{-1}$. Xiong et al. [41] obtained particles sizes ranging from approx. $325 \mathrm{~nm}$ to $600 \mathrm{~nm}$ (by intensity) with lignin concentrations from 0.5 to $2 \mathrm{mg} \cdot \mathrm{mL}^{-1}$ and flow rate of $4 \mathrm{~mL} \cdot \mathrm{min}^{-1}$. Wang et al. [14] observed that the LPs size increased from $100 \mathrm{~nm}$ to $800 \mathrm{~nm}$, with the increase of the lignin concentration from $1.0 \mathrm{mg} \cdot \mathrm{mL}^{-1}$ to $4.0 \mathrm{mg} \cdot \mathrm{mL}^{-1}$. Chen et al. [22] observed that the particle size increased proportionately with the increase in the initial concentration of lignin until a concentration of $80 \mathrm{mg} \cdot \mathrm{mL}^{-1}$, where LPs of $210 \mathrm{~nm}$ were obtained, above this concentration, the size of the LPs remained practically unchanged.

Particle size influences many properties of particulate materials (e.g. stability and reactivity) while the PDI is indicative of the homogeneity of the samples. In general, PDI below 0.2 indicates that the sample exhibit a good homogeneity [42]. LNPs presented a PDI of $0.15 \pm 0.02$, and therefore the sample can be considered monodisperse. For LMPs the PDI value was $0.20 \pm 0.04$ confirming that also LMPs have a homogeneous distribution. These results are in agreement with other works using different types of lignin, with PDI values ranging between 0.1 and $0.5[21-23,43]$.

On the other hand, the zeta potential is indicative of the surface charge of the particles that can be related to the chemical and surface composition of the particles. Besides influencing their reactivity, the zeta potential also influences their colloidal stability being particles with zeta potentials more positive than $+30 \mathrm{mV}$ or more negative than $-30 \mathrm{mV}$ normally considered stable $[33,42]$. High zeta-potential values (positive or negative) also indicate an adequate double layer electrical repulsion between the particles, which avoids their aggregation $[27,28]$. The value obtained for LNPs was $-31.94 \pm 4.61 \mathrm{mV}$. On the other hand, the value obtained for LMPs was $-18.80 \pm 3.18 \mathrm{mV}$. The negative zeta potential of LPs can be related to the negatively charged phenols and, to some extent, the adsorption of hydroxyl ions $[27,28]$.

Table 1

Particle size (by intensity and number), polydispersity index (PDI) and zeta potential of LNPs and LMPs.

\begin{tabular}{lllll}
\hline & \multicolumn{2}{l}{ Particle size $(\mathrm{nm})$} & PDI & Zeta potential $(\mathrm{mV})$ \\
\cline { 2 - 3 } & Intensity & Number & & \\
\hline LNPs & $149.22 \pm 5.16^{\mathrm{a}}$ & $75.74 \pm 6.27^{\mathrm{a}}$ & $0.15 \pm 0.02^{\mathrm{a}}$ & $-31.94 \pm 4.61^{\mathrm{a}}$ \\
LMPs & $323.67 \pm 36.91^{\mathrm{b}}$ & $215.06 \pm 31.48^{\mathrm{b}}$ & $0.20 \pm 0.04^{\mathrm{b}}$ & $-18.80 \pm 3.18^{\mathrm{b}}$ \\
\hline
\end{tabular}

Values reported are means $\pm \mathrm{sd}$. Different letters $(\mathrm{a}-\mathrm{b})$ in the same column indicate a statistically significant difference $(\mathrm{p}<0.05)$. 


\subsection{Morphology of LPS}

The morphology of LPs was analyzed by TEM. Fig. 1 shows the images of LNPs and LMPs. Both LNPs and LMPs presented sizes in the range of the values determined by DLS (when determined by number). LPs also presented symmetric and spherical shape, that is resultant of the methodology used for production. This is in good agreement with the results obtained by Qian et al. [2] and Xiong et al. [41] that produced LNPs with uniform spherical shape via solvent displacement method using other solvents. On the other hand, some authors have used other production methods to obtain lignin-based NPs, but usually an irregular shape is obtained $[8,20,44]$. The good solubility of organosolv lignin in ethanol and their high purity [31] allowed the self-assembly process of lignin during the solvent exchange process resulting in spherical nano- and micro-particles.

\subsection{Chemical structure}

The infrared spectra of LNPs and LMPs, as well as of the raw lignin, are presented in Fig. 2. All samples (lignin and LPs) showed a strong wide absorption band around $3400 \mathrm{~cm}^{-1}$, originated from the $\mathrm{O}-\mathrm{H}$ stretch. This band is related to the presence of alcoholic and phenolic hydroxyl groups involved in hydrogen bonds. The absorption bands located at 2930 and $2850 \mathrm{~cm}^{-1}$ arising from the symmetrical and asymmetrical $\mathrm{C}-\mathrm{H}$ stretching of the methyl and methylene groups were also founded in the three samples (lignin and LPs) [45-47].

The absorption band at $1695 \mathrm{~cm}^{-1}$ identified in lignin and both LPs samples is due to the $\mathrm{C}=\mathrm{H}$ stretch in conjugated aldehydes and carboxyl groups [45]. Additionally, the absorption band observed around $1655 \mathrm{~cm}^{-1}$ for lignin and LPs was assigned to stretching vibrations of conjugated carbonyl groups [48]. The bands at around 1603, 1513, and $1427 \mathrm{~cm}^{-1}$, correspond to the aromatic skeletal vibrations [49,50]. The band at around $1458 \mathrm{~cm}^{-1}$ is related to the vibration in $-\mathrm{CH}_{3}$ and $\mathrm{CH}_{2}$ - groups caused by asymmetric $\mathrm{C}-\mathrm{H}$ deformations [47]. An aliphatic $\mathrm{C}-\mathrm{H}$ stretch in $\mathrm{CH}_{3}$ groups was observed at $1360 \mathrm{~cm}^{-1}$. Phenolic $\mathrm{OH}$ groups were also shown by absorption bands at $1360 \mathrm{~cm}^{-1}$, $1328 \mathrm{~cm}^{-1}$ and $1207 \mathrm{~cm}^{-1}$ [51].

Several bands were attributed to $S$ and $G$ structures of lignin. Syringyl ring breathing with $\mathrm{C}-\mathrm{O}$ stretching are presented at around $1328 \mathrm{~cm}^{-1}$. In addition to this, another signal characteristic of $\mathrm{C}-\mathrm{H}$ bonds in the aromatic rings ( $\mathrm{S}$ units) was presented at $1119 \mathrm{~cm}^{-1}$ [52]. A typical G bands was detected at around $1260 \mathrm{~cm}^{-1}$ [45]. A band related to in-plane deformations of $\mathrm{C}-\mathrm{H}$ bonds in the aromatic rings and deformation vibrations of $\mathrm{C}-\mathrm{O}$ bonds in primary alcohols
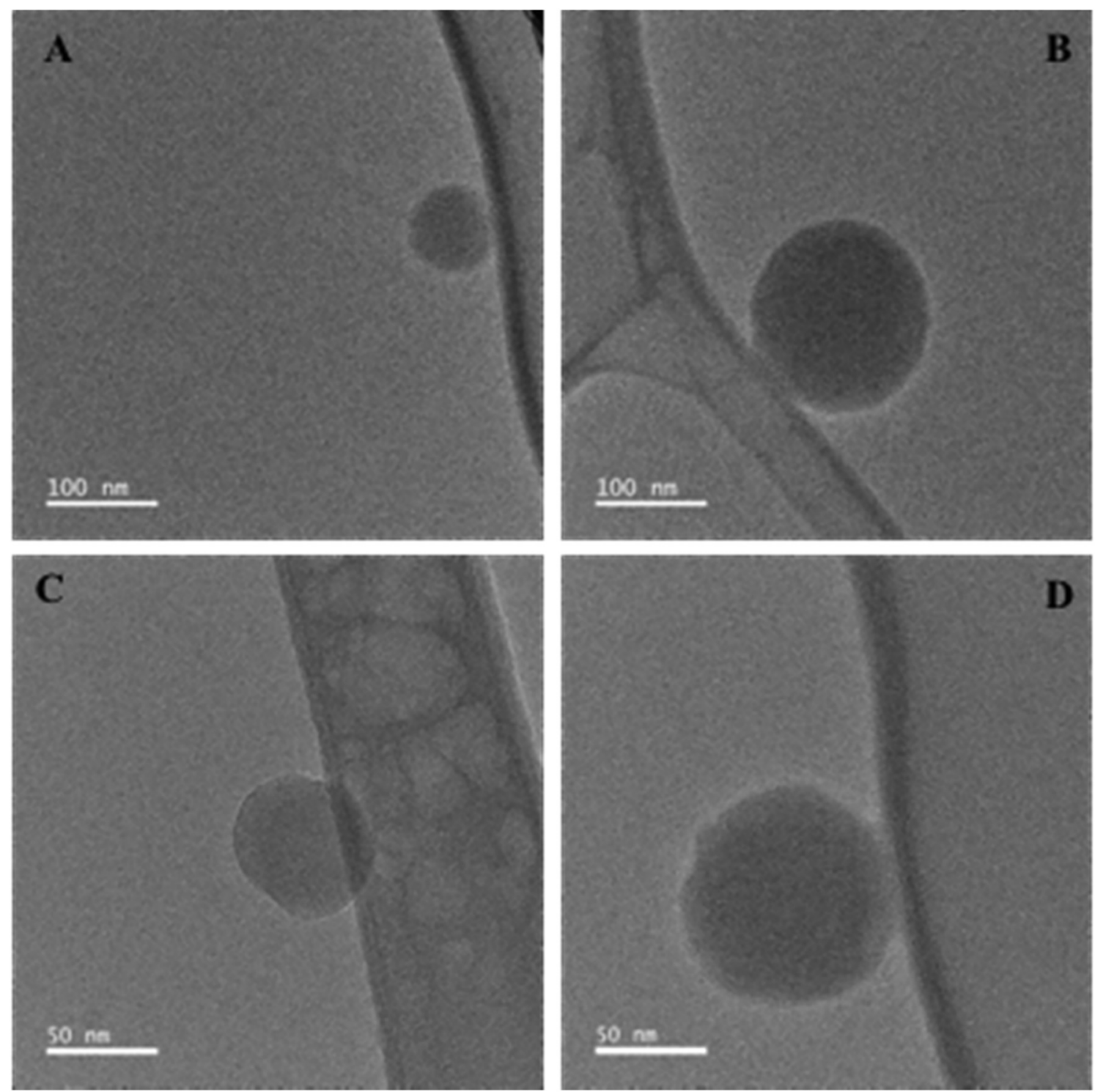

Fig. 1. TEM images of LNPs (A, C) and LMPs (B, D) at a magnification of $100,000 \times(A, B)$ and $200,000 \times(C, D)$. 


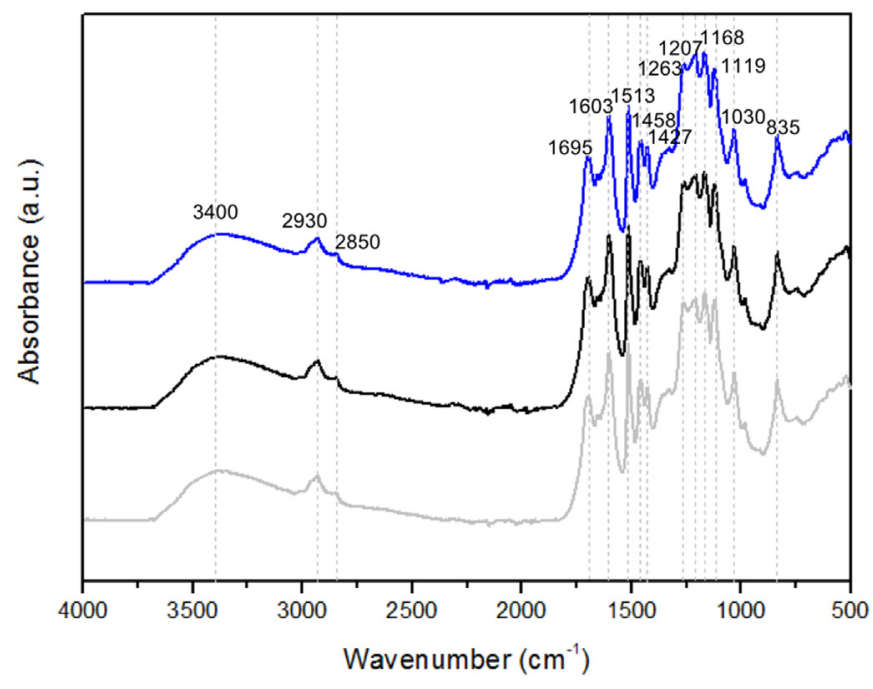

Fig. 2. ATR-FTIR spectra of LNPs (grey lines), LMPs (black lines) and lignin (blue lines)

appeared at $1030 \mathrm{~cm}^{-1}$ [53]. In addition, another important spectral around $835 \mathrm{~cm}^{-1}$ corresponded to $\mathrm{C}-\mathrm{H}$ deformations ring vibrations and $\mathrm{C}-\mathrm{OH}$ out-of-plane bending $(\mathrm{C}-\mathrm{H}$ out-of-plane in positions 2 and 6 of $\mathrm{S}$ units, and in all position of $\mathrm{H}$ units). The presence of the band at $1168 \mathrm{~cm}^{-1}$ was assigned to $\mathrm{H}$ unit, which is typical to the HGS type [54]. Thus, this band confirmed that the lignin used for producing LPs in this study is of the HGS type. In addition, the band at around $1168 \mathrm{~cm}^{-1}$ indicated $\mathrm{C}-\mathrm{O}$ vibrations in conjugated ester groups. In this work, both LPs and lignin showed similar spectral features, revealing no chemical changes during the formation of the nano- and microparticles. A similar behavior was observed by Xiong et al. [41] for LPs produced by the solvent displacement method through adding an antisolvent (water).

\subsection{Thermal properties}

Thermogravimetric analysis was performed to evaluate the thermal degradation behavior of LPs. Normally, the thermal degradation of lignin takes place from $185^{\circ} \mathrm{C}$ to $500{ }^{\circ} \mathrm{C}$; this fact is due to the complex structure of lignin with phenolic hydroxyl, carbonyl groups and benzylic hydroxyl, which are connected by straight links [55]. TG and DTG profiles are shown in Fig. 3. The first peak of DTG curve occurred around $70{ }^{\circ} \mathrm{C}$ ( $<3 \%$ of weight loss) and correspond to the evaporation of residual moisture present in the samples. Regarding the lignin degradation, three main weight loss stages were observed on LPs. The first one appears at $139{ }^{\circ} \mathrm{C}$ (peak 1), the second one at $295{ }^{\circ} \mathrm{C}$ (peak 2) and the third on at $366{ }^{\circ} \mathrm{C}$ (peak 3) for the LNPs; and at $144{ }^{\circ} \mathrm{C}$ (peak 1), $295{ }^{\circ} \mathrm{C}$ (peak 2) and $373{ }^{\circ} \mathrm{C}$ (peak 3 ) for the LMPs. Regarding lignin, the first degradation peak was less evident, while the other two occurred at $293^{\circ} \mathrm{C}$ and $377^{\circ} \mathrm{C}$. In general, the thermal degradation behavior of LPs was similar to the one of raw lignin.

Some studies have reported that the decomposition of the lignin structure starts at relatively low temperatures $\left(150-290{ }^{\circ} \mathrm{C}\right)$, as observed in this work. It is thought that the first decomposition step is due to the dehydration of the hydroxyl groups located in the benzyl group. It was reported that the cleavage of $\alpha$ - and $\beta$-aryl-alkyl ether linkages occur around 150 and $300{ }^{\circ} \mathrm{C}[6,56]$. Aliphatic side chains start splitting off from the aromatic ring at around $300{ }^{\circ} \mathrm{C}$, while at $370-400{ }^{\circ} \mathrm{C}$ occurs the carbon-carbon cleavage between lignin structural units $[57,58]$. Finally, at temperatures higher than $500{ }^{\circ} \mathrm{C}$, the typical weight losses in TG curves flatten out, with a slow release of the volatile products (such as $\mathrm{CO}, \mathrm{CO}_{2}, \mathrm{CH}_{4}, \mathrm{H}_{2}$ formed during lignin

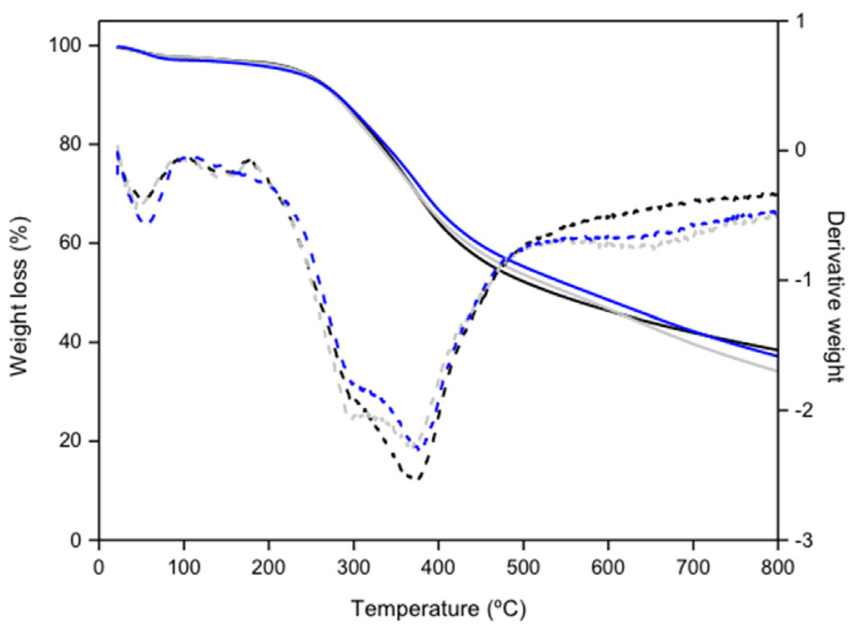

Fig. 3. TG (solid lines) and DTG (dotted lines) curves of LNPs (grey lines); LMPs (black lines) and lignin (blue lines).

pyrolysis), before the formation of (30-50\%) char [6,59]. In this work, around $40 \%$ unvolatilized lignin at $800{ }^{\circ} \mathrm{C}$ (char residue) was observed, due to the formation of highly condensed aromatic structures.

Another thermal property evaluated was the glass transition $\left(T_{g}\right) . T_{g}$ values of LPs were investigated and compared with the raw lignin. Results revealed that the $T_{g}$ values are influenced by conformation of the materials and by the particle size. LPs presented a higher $T_{g}$ than lignin. Besides, the $T_{g}$ of LNPs was higher than the $T_{g}$ of LMPs. For lignin the $T_{g}$ value was $81.5^{\circ} \mathrm{C}$, while for LMPs and LNPs the $T_{g}$ values were $103.9{ }^{\circ} \mathrm{C}$ and $124.3^{\circ} \mathrm{C}$, respectively, showing that a smaller particle size leads to higher $T_{g}$ values.

$T_{g}$ is directly related to the mobility of the macromolecular chains, which may be affected by a complex interplay between several factors including the molecular weight of the material, the presence of chemical or physical crosslinks, and the presence of strong intermolecular interactions between the macromolecular chains such as intermolecular hydrogen bonds [15]. Gupta et al. [60] reported similar results for LPs produced from low sulfonated lignin (lignin protobind-1000) using acid precipitation method, where the $T_{g}$ value of LNPs $\left(153.7^{\circ} \mathrm{C}\right.$ ) was higher than the $T_{g}$ of lignin $\left(151.5^{\circ} \mathrm{C}\right)$. Overney et al. [61] also showed that smaller particle sizes lead to an increase of $T_{g}$ values. They explained this behavior by the mechanical confinement of polymers, which result in the increased amount of thermal energy needed to cause the transition.

\subsection{Antioxidant activity}

Lignin, due to their phenolic hydroxyl groups, is an effective free radical scavenger, which can reduce oxygen radicals and stabilize oxidation reactions [31,62-64]. Table 2 presents the results of the ABTS assay, in

Table 2

IC $_{50}$ values of LNPs, LMPs, lignin and commercial antioxidants (Trolox, BHT, BHA, AA and GA) obtained by the ABTS assay.

\begin{tabular}{ll}
\hline Compounds & $\mathrm{IC}_{50}\left(\mathrm{mg} \cdot \mathrm{mL}^{-1}\right)$ \\
\hline Trolox & 0.013 \\
BHT & 0.024 \\
BHA & 0.010 \\
Lignin & 0.027 \\
AA & 0.013 \\
GA & 0.003 \\
LNPs & 0.088 \\
LMPs & 0.101 \\
\hline
\end{tabular}


terms of $\mathrm{IC}_{50}$. Results showed that lignin presented an $\mathrm{IC}_{50}$ of $0.027 \mathrm{mg} \cdot \mathrm{mL}^{-1}$. The commercial antioxidants Trolox, BHA, AA and GA presented values of $0.013 \mathrm{mg} \cdot \mathrm{mL}^{-1}, 0.010 \mathrm{mg} \cdot \mathrm{mL}^{-1}, 0.013 \mathrm{mg} \cdot \mathrm{mL}^{-1}$ and $0.003 \mathrm{mg} \cdot \mathrm{mL}^{-1}$, respectively, showing a higher antioxidant potential. However, the $\mathrm{IC}_{50}$ value obtained for lignin was very close to that obtained for BHT (commercial antioxidant) that was $0.024 \mathrm{mg} \cdot \mathrm{mL}^{-1}$, confirming that lignin presents a remarkable radical scavenging capacity. The LNPs and LMPs presented similar $(\mathrm{p}>0.05) \mathrm{IC}_{50}$ values $\left(0.088 \mathrm{mg} \cdot \mathrm{mL}^{-1}\right.$ and $0.101 \mathrm{mg} \cdot \mathrm{mL}^{-1}$, respectively) showing a lower antioxidant potential (in terms of $\mathrm{IC}_{50}$ ) when compared to commercial antioxidants and raw lignin.

However, it is important to highlight that LPs were dispersed in water (to avoid their disintegration), while the reference antioxidants, including lignin, were dispersed in $60 \%$ (v/v) of ethanol before analysis, which may influenced the results. For example, Lu et al. [17] compared the RSA of nanoscale lignin and lignin using DPPH method. The results showed an improvement of RSA for LNPs when compared to the lignin. However, these results can be related to the way of preparation of the raw lignin in the assay since all samples were dispersed in water, including organosolv lignin, and filtered through a $0.45 \mu \mathrm{m}$ membrane.

On the other hand, since other factors could influence the antioxidant activity of LPs, such as the arrangement of the phenolic groups in lignin during particle formation, RSA of LPs was evaluated under higher reaction times for different concentrations (Fig. 4). Similar antioxidant potential was observed for LNPs and LMPs. The ABTS inhibitory effect increased for higher reaction time and LPs' concentration. The antioxidant activity in terms of percentage of inhibition of the ABTS radicals at $0.2 \mathrm{mg} \cdot \mathrm{mL}^{-1}$ for $60 \mathrm{~min}$ of reaction achieved values of $96.11 \pm$ $0.17 \%$ and $93.8 \pm 0.29 \%$ for the LNPs and LMPs, respectively. At $0.1 \mathrm{mg} \cdot \mathrm{mL}^{-1}$ for $60 \mathrm{~min}$ of reaction, the percentage of inhibition of ABTS radicals achieved values of $84.63 \pm 1.63 \%$ and $82.83 \pm 0.68 \%$ for the LNPs and LMPs, respectively. Thus, the $\mathrm{IC}_{50}$ values of LNPs and
LMPs varied from 0.088 to $0.030 \mathrm{mg} \cdot \mathrm{mL}^{-1}$ and 0.101 to $0.020 \mathrm{mg} \cdot \mathrm{mL}^{-1}$, for 6 and $60 \mathrm{~min}$ of reaction, respectively (data not shown). Therefore, the results showed the potential of using LPs as a natural antioxidant compound, however no major differences are observed when LNPs are compared with LMPs. Yearla and Padmasree [18] and Zhang et al. [43] have compared the effectiveness of RSA of LPs in relation to the raw lignin. In the work of Zhang et al. [43], they showed an increase in the $\mathrm{IC}_{50}$ as the size of the LNPs increased for two tested sources (corncob lignin from enzymatic mild acidolysis CC and steam explosion lignin - SE); however, for SE lignin it was observed that raw lignin presented a lower $\mathrm{IC}_{50}$ than larger LNPs, with 140 and $160 \mathrm{~nm}$ in size.

\subsection{Antimicrobial activity}

A comparative study of the growth of bacteria (Escherichia coli 0157: H7 and Salmonella enterica serovar Typhimurium) under normal conditions (control) and under the presence of LNPs and LMPs was performed. Fig. 5 presents the growth curve of $E$. coli and S. Typhimurium under these conditions. In general, the results showed that LPs have an inhibitory effect on microbial growth, which was more prominent to LMPs.

Fig. 5A and B shows the results obtained for E. coli 0157:H7 and S. Typhimurium, respectively, incubated with $1.0 \mathrm{mg} \cdot \mathrm{mL}^{-1}$ LNPs. First, it was observed an increase of $2 \mathrm{~h}$ in the lag phase for E. coli 0157:H7 grown in the presence of the LNPs, in relation to the control. In the case of $S$. Typhimurium, the increase was of $3 \mathrm{~h}$. It was also observed a reduction in the maximum increment of the bacteria, which is related to the proliferation of the bacteria. For $E$. coli 0157:H7 incubated with $1 \mathrm{mg} \cdot \mathrm{mL}^{-1}$ LNPs (Fig. 5A), a maximum growth (measured through the OD of the bacterial culture) of $0.61 \pm 0.11$ was observed, while in the control conditions the OD was $1.14 \pm 0.07$, therefore, an inhibition
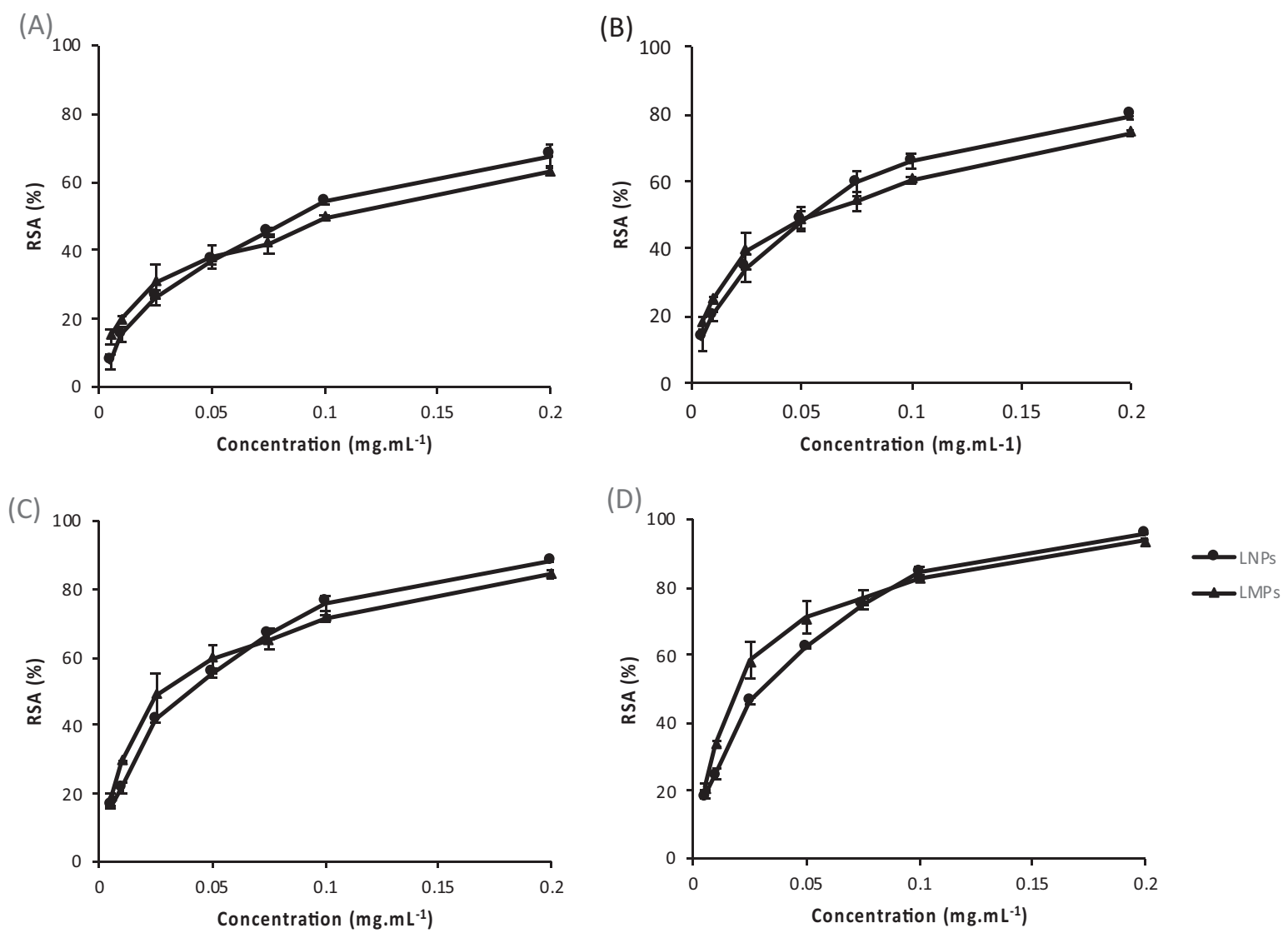

Fig. 4. Radical scavenging activity (RSA) of LNPs and LMPs after $6 \mathrm{~min}(\mathrm{~A}), 15 \mathrm{~min}(\mathrm{~B}), 30 \mathrm{~min}(\mathrm{C})$ and $60 \mathrm{~min}$ (D) of reaction. 
(A)

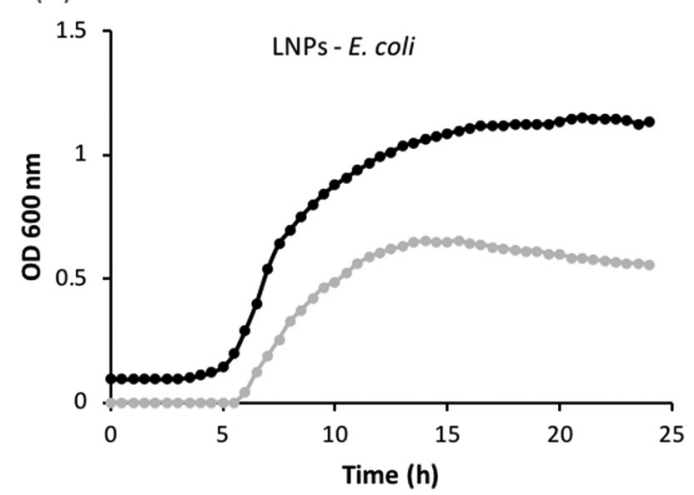

(C)

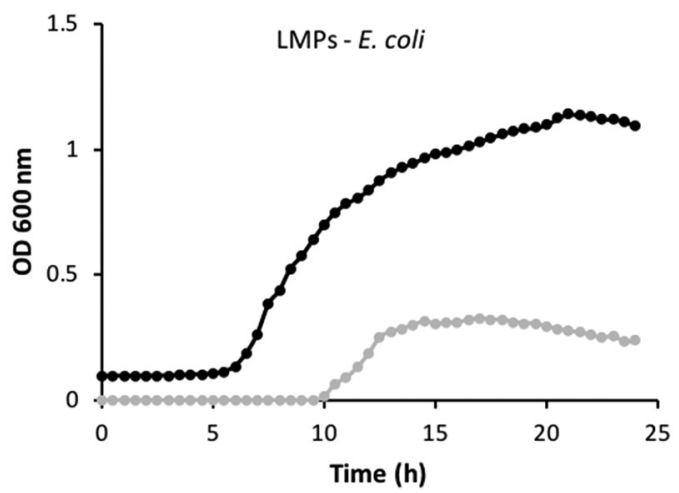

(B)

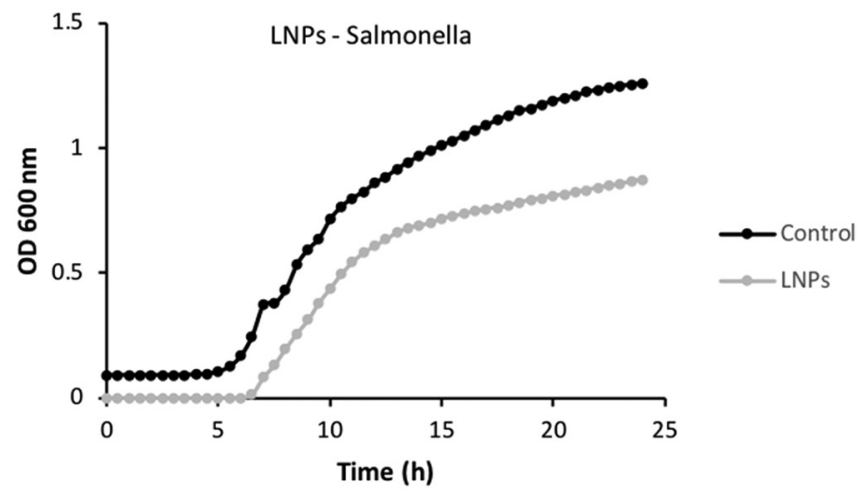

(D)

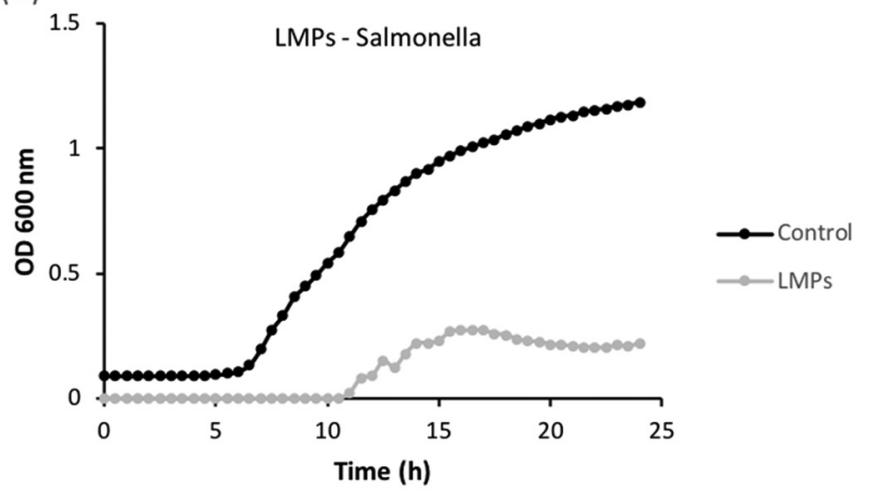

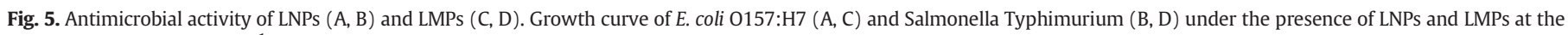
concentration of $1.0 \mathrm{mg} \cdot \mathrm{mL}^{-1}$ (grey lines). Bacteria growth curve without LPs was used as positive control (black lines).

of $46.5 \%$ in the cellular proliferation. Similar behavior was observed for Salmonella growth at the same conditions (Fig. 5B). In this case, the $\log$ phase achieved a maximum OD of $1.26 \pm 0.02$ under control conditions, while in the presence of the $1 \mathrm{mg} \cdot \mathrm{mL}^{-1} \mathrm{LNPs}$ the maximum OD was $0.82 \pm 0.06$, i.e. an inhibitory effect of $34.9 \%$.

LMPs presented a higher inhibitory effect in the bacterial growth than LNPs. E. coli 0157:H7 growth curve incubated with LMPs presented a shorter log phase when compared with growth curve of $E$. coli 0157 : $\mathrm{H} 7$ under control conditions (Fig. 5C). Control bacterial culture reached a maximum growth of $1.20 \pm 0.06$ compared to $0.29 \pm 0.01$ for bacterial cells treated with $1 \mathrm{mg} \cdot \mathrm{mL}^{-1} \mathrm{LMPs}$, respectively. In addition, the $E$. coli 0157:H7 growth curve showed a significant increase of the duration of the lag phase, as the control presented a lag phase of $4.8 \mathrm{~h}$, while the LMP-treated bacteria were $11.5 \mathrm{~h}$, indicating that in the presence of LMPs, E. coli 0157:H7 started its proliferation later than the control culture. These results suggest that the concentration of particles has an influence on this effect.

The same behavior was observed for Salmonella growth at the same conditions (Fig. 5D). Under the influence of LMPs, S. Typhimurium presented a shortening log phase when compared with the control growth curve, which indicates a bacteriostatic effect. Control bacterial culture reached a maximum growth of $1.29 \pm 0.02$ compared to $0.23 \pm 0.01$, for bacterial cells treated with $1 \mathrm{mg} \cdot \mathrm{mL}^{-1} \mathrm{LMPs}$, respectively. The lag phase in Salmonella control growth curve has a duration of $5 \mathrm{~h}$, while it extended until $11 \mathrm{~h}$ for $1 \mathrm{mg} \cdot \mathrm{mL}^{-1} \mathrm{LMPs}$.

The antimicrobial effect of LPs can be explained by the fact that lignin is an important source of antibacterial compounds, such as phenolic monomer fragments (high content of $p$-coumaric and ferulic acids). Phenolic fragments containing a double bond in $\alpha, \beta$ positions of the side chain and a methyl group in the $\gamma$ position that show, in general, the inhibitory effect [65]. This antimicrobial effect has been reported to be more effective against gram-positive bacteria than gramnegative, such as E. coli and Salmonella, and filamentous fungi [66]. Other studies using LPs incorporated in polymer-based films also showed their antimicrobial activity [67,68]. Yang et al. [68] also verified an antimicrobial effect of LNPs in the $\mathrm{CH}$, PVA and $\mathrm{CH} / \mathrm{PVA}$ films against two bacterial plant pathogens (Xanthomonas arboricola pv. pruni and Pectobacterium carotovorum subsp. odoriferum). In another work, Yang et al. [69] evaluated the antimicrobial effect of LNPs in PVA/CH hydrogels and verified that $\mathrm{CH}$ hydrogels, as well as CH/PVA/LNPs hydrogels had an antimicrobial effect against E. coli, but for Staphylococcus aureus LNPs showed an additional antimicrobial effect. On the other hand, only hydrogels containing LNPs showed a slight antimicrobial effect against $S$. epidermidis (a gram-negative bacteria able to form biofilm) in planktonic conditions, but no effect was observed in biofilm formation.

The particle size and specific surface influence the antimicrobial activity of NPs [70]. The size of the LPs showed to influence the antimicrobial effect on the studied bacteria, being the LMPs the ones with more effect. Both, LMPs and LNPs present a huge surface area and, therefore, a great amount of functional and polyphenolic side chains on their surface, however smaller particles (LNPs) would be expected to have higher antimicrobial activity than larger particles (LMPs), since the larger surface area from LNPs increases the contact area and therefore their antimicrobial effect. However, in this case, the opposite behavior was observed, that can be justified by the surface charge closer to zero of LMPs $(-18.80 \mathrm{mV})$ when compared with LNPs $(-31.94 \mathrm{mV})$. It is known that bacteria (cell membrane negatively charged) have more affinity with materials with positive or near zero surface charges than negatively charged materials. Arakha et al. [71] showed that negatively charged NPs presented insignificant antimicrobial activity. But, when these NPs were coated with positively charged chitosan, the 
antimicrobial activity significantly increased, which is related to the no adherence of bacteria to the negatively charged ones. So, the surface charge may have influenced the way the particles are interacting with the cell membrane and thus influencing the effect of the phenolic groups of lignin on bacterial damage and lysis [70,72].

\subsection{Cytotoxicity}

The cytotoxicity of lignin particles was indirectly determined, through the resazurin or MTT assays, measuring fluorescence or absorbance, respectively. The cellular viability of Caco-2 cells was measured after 4 or 24 h of incubation at different concentrations. Although LPs were made of the same starting material, they can present different behavior due to the differences observed in their charge and size, resulting in potential changes in the cell-NP interactions [73,74].

After $4 \mathrm{~h}$ of contact, all tested concentrations of LNPs and LMPs demonstrated cellular compatibility, i.e. more than $70 \%$ of cell viability, in both assays (Fig. 6A and B). However, after $24 \mathrm{~h}$ of contact, a concentration-responsive effect is observed, in both assays (Fig. 6B and $\mathrm{D}$ ), on the cell viability. At the concentration of $0.2 \mathrm{mg} \cdot \mathrm{mL}^{-1}$ (the highest concentration tested), both LPs presented a value of cell viability below 70\% that is considered toxic [75]. In general, the results showed that LPs are not cytotoxic after $4 \mathrm{~h}$ of contact with cells, but for longer contact times, such as $24 \mathrm{~h}$, concentrations below $0.1 \mathrm{mg} \cdot \mathrm{mL}^{-1}$ must be used. Moreover, it was demonstrated that the size of lignin particles does not present a significant effect on their cytotoxic behavior, for the majority of tested conditions. When significant results are observed, LMPs are generally more toxic than LNPs, which can be explained by the surface charge of the LMPs, as verified by the zeta potential. This is in agreement with other works that showed that surface charge is one of the major factors affecting the toxicity of particles, in some cases with a higher effect when compared with size [76]. Figueiredo et al. [9] studied the in vitro cytocompatibility of LNPs, at different concentrations for 6 and $24 \mathrm{~h}$ of incubation, using different cancer cell lines. They verified that in general pure LNPs caused no cytotoxicity in the cell lines, with exception of the human umbilical vein cell line (EA.hy926), upon $24 \mathrm{~h}$ of incubation with $250 \mu \mathrm{g} \cdot \mathrm{mL}^{-1}$ of pure LNPs where the cell viability decreased to around 70\%. Chen et al. [22] used NIH-3 T3 cell, a standard mouse fibroblast, to assess the cytotoxicity of LNPs and observed that the particles induced some cytotoxicity in a concentration-dependent manner. Overall, the results of the present work suggested that LPs induce some cytotoxicity in Caco-2 cell line in a time-dependent and concentration-dependent manner. Based on these results, concentrations of LPs $\leq 0.1 \mathrm{mg} \cdot \mathrm{mL}^{-1}$ were chosen for treating cells in further experiments.

\subsection{Cellular antioxidant activity}

The physicochemical properties of the nano- or micro-particles can interfere with the biological activities, such as the production of ROS, inducing particles-associated toxicity. This oxidative stress can be due to acellular factors, including particle size, surface, composition and presence of metals, and/or cellular responses, such as mitochondrial respiration, which lead to ROS-induced damage [77-79].

The effect of LPs on the intracellular ROS content was evaluated in Caco- 2 cells without inducing exogenous oxidative stress. The cells were incubated with different concentrations of LPs for 4 or $24 \mathrm{~h}$. In Fig. 7, the effect of particles' size on intracellular ROS production is not clear. Among all conditions tested, only at a concentration of $0.01 \mathrm{mg} \cdot \mathrm{mL}^{-1}$ after $24 \mathrm{~h}$ of incubation the difference between LNPs
(A)

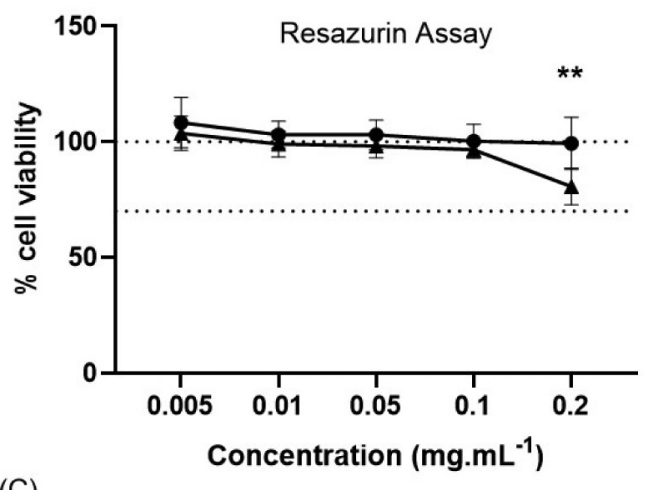

(C)

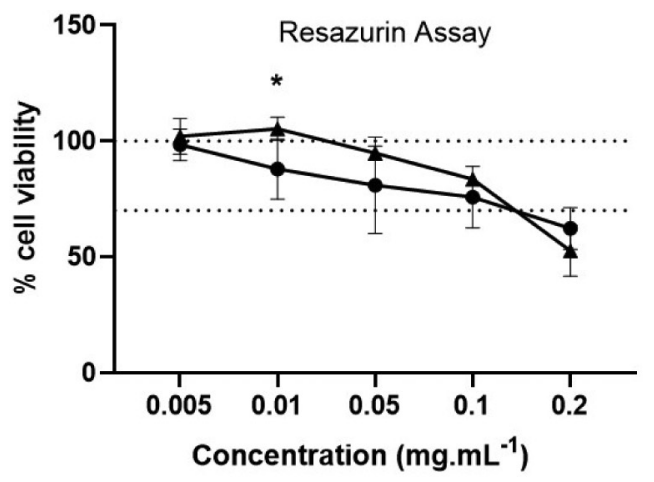

(B)

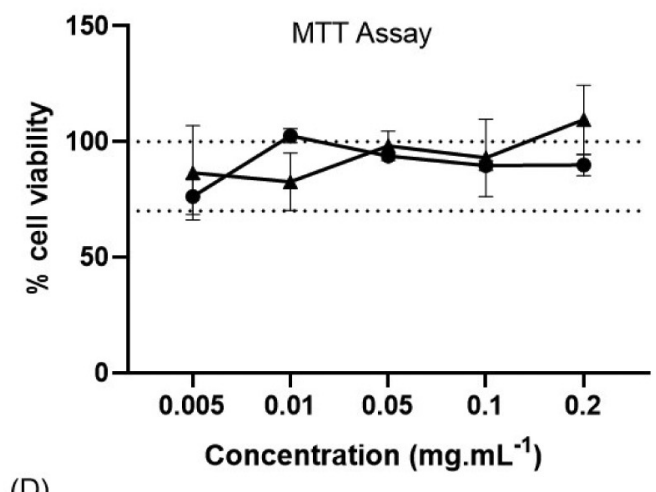

(D)

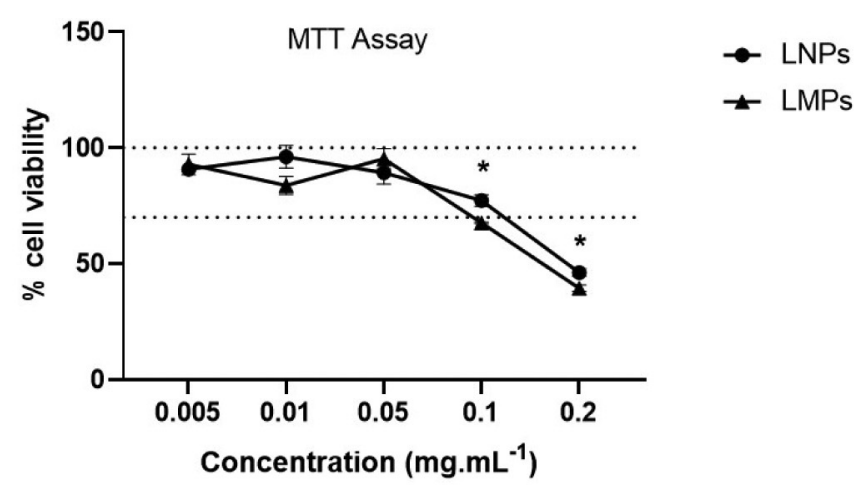

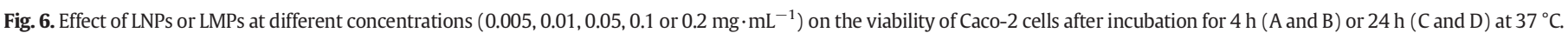

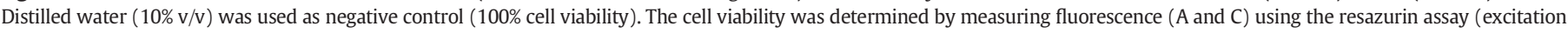

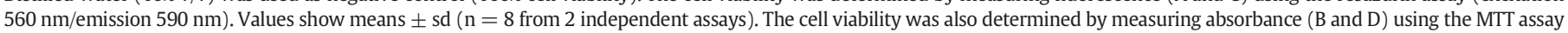
(absorbance $570 \mathrm{~nm})$. Values show means $\pm \mathrm{sd}(\mathrm{n}=3)$. Statistical significance determined using the Holm-Sidak method; ${ }^{*}$ for $\mathrm{p}<0.05$ and ${ }^{* *}$ for $\mathrm{p}<0.01$. 
(A)

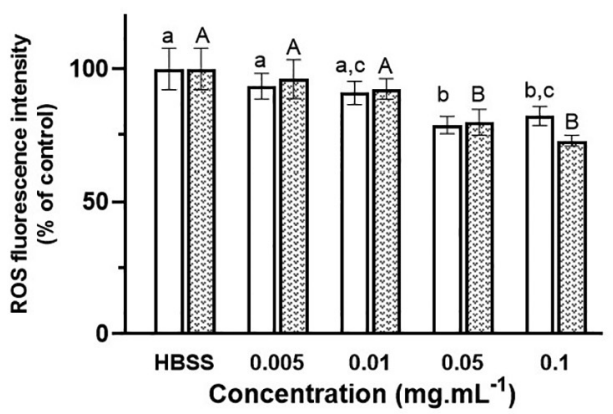

(B)

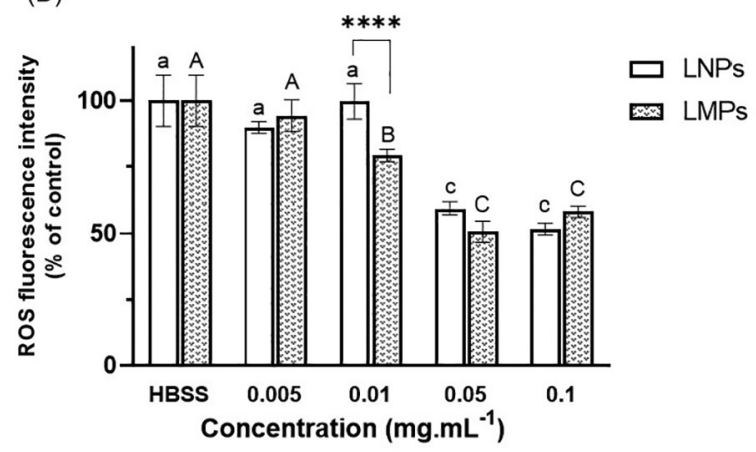

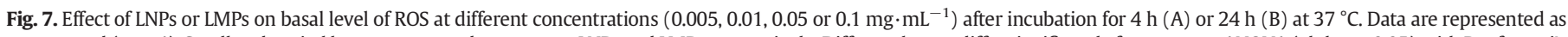

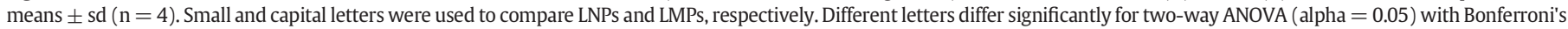
multiple comparisons test, ${ }^{* * * *}$ for $\mathrm{p}<0.0001$.

and LMPs is clear (Fig. 7B). LPs decreased the basal level of ROS, comparing with the control (cells treated with HBSS), in a concentration and time-dependent manner. This result suggests that at higher concentrations, the LPs are able to neutralize the ROS produced naturally by the cells demonstrating a possible antioxidant effect (intracellular) of LPs against ROS. This corroborates the antioxidant capacity of the LPs demonstrated in the ABTS assay.

To evaluate the protective effect of LPs, Caco- 2 cells were pre-treated with LPs at different concentrations for 4 or $24 \mathrm{~h}$ and then incubated with $0.25 \mathrm{mM} \mathrm{H}_{2} \mathrm{O}_{2}$, an intracellular oxidizing agent. The $\mathrm{H}_{2} \mathrm{O}_{2}$ was selected according to literature using the same cell line [39]. Cells treated with $\mathrm{HBSS}$ and stressed with $\mathrm{H}_{2} \mathrm{O}_{2}$ were used as the positive control. As can be observed in Fig. 8, cells pre-treated with non-toxic concentrations of LPs significantly reduced ROS level in a concentrationdependent manner, compared with cells pre-treated with HBSS (control). Moreover, $4 \mathrm{~h}$ of pre-treatment appear as sufficient time to inhibit ROS production (Fig. 8A). As previously observed, the particles size does not play a significant role in the antioxidant activity since overall no significant differences were observed between LNPs and LMPs for the same condition. When significant results are obtained (0.005 and $0.01 \mathrm{mg} \cdot \mathrm{mL}^{-1}$, for $4 \mathrm{~h}$ of incubation), LMPs tend to be more effective than LNPs on the ROS inhibition. These results reinforce the results obtained for antimicrobial activity and cytotoxicity, where the LMPs showed to be more reactive than LNPs, which can be explained by the surface charge of the particles. In this study, the antioxidant activity (protective effect) of LPs in $\mathrm{H}_{2} \mathrm{O}_{2}$-stimulated Caco-2 cells was clearly demonstrated.

\section{Conclusions}

In the present study, it was demonstrated that organosolv lignin extracted from corncob can be successfully employed for the production of LPs using a green synthesis method. This process allowed the production of LPs with different sizes ( $75 \mathrm{~nm}$ and $215 \mathrm{~nm}$ ), round shape and low polydispersity that were optimized and further characterized. The size's effect of LPs was observed in some properties. In general, no differences in the bonding pattern and functional group of LPs were observed through FTIR analysis, proving that the lignin structure did not change with the development of particles. However, thermal analyses showed that smaller particle size led to higher $T_{g}$ values. Both LPs presented similar antioxidant potential and the bacteriostatic effect against $E$. coli 0157:H7 and Salmonella was more pronounced in the LMPs than LNPs. The cytotoxicity was assessed due to the lack of cytotoxicity tests of LPs toward human cells and results showed that LPs are nontoxic, at concentrations below $0.1 \mathrm{mg} \cdot \mathrm{mL}^{-1}$, after $24 \mathrm{~h}$ of incubation with Caco- 2 cells. Moreover, the particle size does not play a significant effect on its cytotoxic behavior of LPs for the majority of tested conditions, but when statistically significant results were observed, LMPs were more toxic than LNPs. LPs also showed an antioxidant effect in the cells by reducing the natural ROS level of cells or protecting them, in a concentration-dependent manner. When significant results were obtained, LMPs tend to be more effective than LNPs on the ROS inhibition. These behavior can be related to the surface charge of LPs. Therefore, LPs with different sizes can have different behaviors in terms of their bioactive potential, and cannot be affirmed that smaller particles
(A)

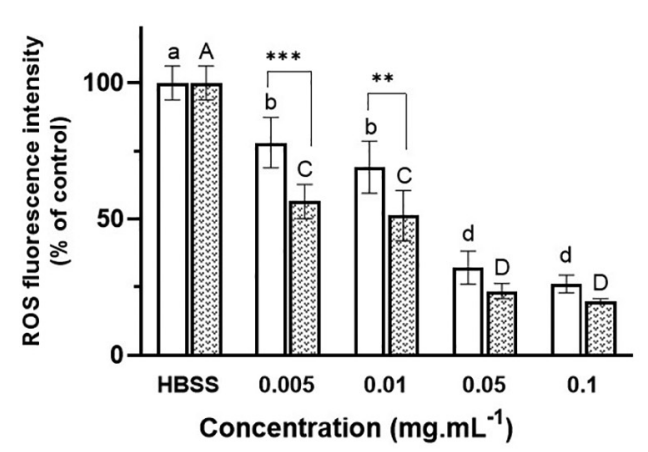

(B)
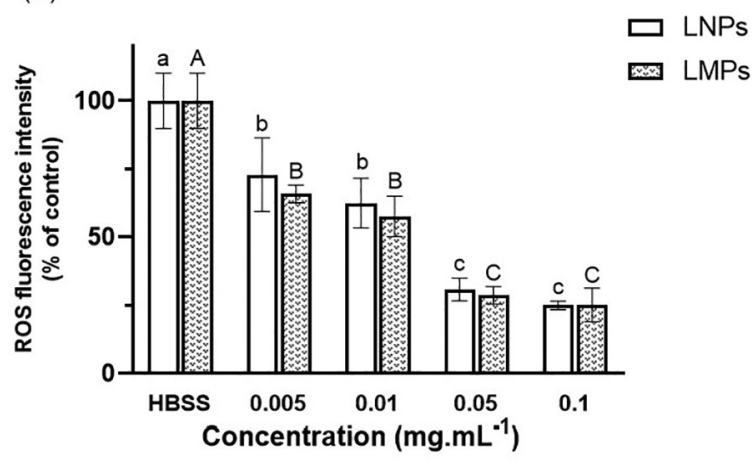

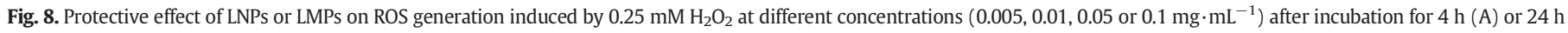

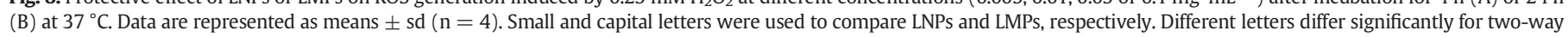
ANOVA (alpha $=0.05$ ) with Bonferroni's multiple comparisons test; ${ }^{* *}$ for $\mathrm{p}<0.01$ and ${ }^{* * *}$ for $\mathrm{p}<0.001$. 
(at the nanoscale) could be considered more reactive. In fact, the obtained results showed a trend of LMPs being more reactive than LNPs. This is in agreement with the guidelines presented by FDA where materials up to $1000 \mathrm{~nm}$ should also be assessed.

\section{CRediT authorship contribution statement}

Filipa M. C. Freitas: Conceptualization; Methodology; Investigation; Formal analysis; Writing - original draft

Miguel A. Cerqueira: Conceptualization; Methodology; Validation; Writing - review \& editing; Supervision

Catarina Gonçalves: Cell assays

Sarah Azinheirob and Alejandro Garrido-Maestu: Antimicrobial assays

António A. Vicente: Resources; Funding acquisition

Lorenzo M. Pastrana: Resources; Funding acquisition

José A. Teixeira: Resources; Funding acquisition

Michele Michelin: Conceptualization; Methodology; Validation; Writing - review \& editing; Supervision.

\section{Acknowledgements}

This study was supported by the Portuguese Foundation for Science and Technology (FCT) under the scope of the strategic funding of UID/ BIO/04469/2020 unit, BioTecNorte operation (NORTE-01-0145-FEDER000004) funded by the European Regional Development Fund under the scope of Norte2020 - Programa Operacional Regional do Norte, and MICRODIGEST project (grant agreement 037716) co-funded by FCT and ERDF through COMPETE2020.

\section{References}

[1] M. Michelin, H.A. Ruiz, D.P. Silva, D.S. Ruzene, J.A. Teixeira, M.L.T.M. Polizeli, in: K.G. Ramawat, J.-M. Mérillon (Eds.), Cellulose From Lignocellulosic Waste BT - Polysaccharides: Bioactivity and Biotechnology, Springer International Publishing, Cham 2014, pp. 1-33, https://doi.org/10.1007/978-3-319-03751-6_52-1.

[2] Y. Qian, Y. Deng, X. Qiu, H. Li, D. Yang, Formation of uniform colloidal spheres from lignin, a renewable resource recovered from pulping spent liquor, Green Chem. 16 (2014) 2156-2163, https://doi.org/10.1039/c3gc42131g.

[3] A. Naseem, S. Tabasum, K.M. Zia, M. Zuber, M. Ali, A. Noreen, Lignin-derivatives based polymers, blends and composites: a review, Int. J. Biol. Macromol. 93 (2016) 296-313, https://doi.org/10.1016/j.ijbiomac.2016.08.030.

[4] C. Li, X. Zhao, A. Wang, G.W. Huber, T. Zhang, Catalytic transformation of lignin for the production of chemicals and fuels, Chem. Rev. 115 (2015) 11559-11624, https://doi.org/10.1021/acs.chemrev.5b00155.

[5] A. Duval, M. Lawoko, A review on lignin-based polymeric, micro- and nanostructured materials, React. Funct. Polym. 85 (2014) 78-96, https://doi.org/10. 1016/j.reactfunctpolym.2014.09.017.

[6] S. Laurichesse, L. Avérous, Progress in polymer science chemical modification of lignins: towards biobased polymers, Prog. Polym. Sci. 39 (2014) 1266-1290, https:// doi.org/10.1016/j.progpolymsci.2013.11.004.

[7] D. Kai, W. Ren, L. Tian, P.L. Chee, Y. Liu, S. Ramakrishna, X.J. Loh, Engineering poly (lactide)-lignin nanofibers with antioxidant activity for biomedical application, ACS Sustain. Chem. Eng. 4 (2016) 5268-5276, https://doi.org/10.1021/ acssuschemeng.6b00478.

[8] C. Frangville, M. Rutkevičius, A.P. Richter, O.D. Velev, S.D. Stoyanov, V.N. Paunov, Fabrication of environmentally biodegradable lignin nanoparticles, ChemPhysChem 13 (2012) 4235-4243, https://doi.org/10.1002/cphc.201200537.

[9] P. Figueiredo, K. Lintinen, A. Kiriazis, V. Hynninen, Z. Liu, T. Bauleth-Ramos, A. Rahikkala, A. Correia, T. Kohout, B. Sarmento, J. Yli-Kauhaluoma, J. Hirvonen, O. Ikkala, M.A. Kostiainen, H.A. Santos, In vitro evaluation of biodegradable ligninbased nanoparticles for drug delivery and enhanced antiproliferation effect in cancer cells, Biomaterials. 121 (2017) 97-108, https://doi.org/10.1016/j.biomaterials. 2016.12.034.

[10] D. Yiamsawas, S.J. Beckers, H. Lu, K. Landfester, F.R. Wurm, Morphology-controlled synthesis of lignin nanocarriers for drug delivery and carbon materials, ACS Biomater. Sci. Eng. 3 (2017) 2375-2383, https://doi.org/10.1021/acsbiomaterials. $7 \mathrm{~b} 00278$.

[11] M.H. Sipponen, H. Lange, M. Ago, C. Crestini, Understanding lignin aggregation processes. A case study: budesonide entrapment and stimuli controlled release from lignin nanoparticles, ACS Sustain. Chem. Eng. 6 (2018) 9342-9351, https://doi.org/ 10.1021/acssuschemeng.8b01652.

[12] N. Chen, L.A. Dempere, Z. Tong, Synthesis of pH-responsive lignin-based Nanocapsules for controlled release of hydrophobic molecules, ACS Sustain. Chem. Eng. 4 (2016) 5204-5211, https://doi.org/10.1021/acssuschemeng.6b01209.
[13] Y. Qian, X. Zhong, Y. Li, X. Qiu, Fabrication of uniform lignin colloidal spheres for developing natural broad-spectrum sunscreens with high sun protection factor, Ind. Crop. Prod. 101 (2017) 54-60, https://doi.org/10.1016/j.indcrop.2017.03.001.

[14] B. Wang, D. Sun, H.-M. Wang, T.-O. Yuan, R.-C. Sun, Green and facile preparation of regular lignin nanoparticles with high yield and their natural broad-spectrum sunscreens, ACS Sustain. Chem. Eng. 7 (2019) 2658-2666, https://doi.org/10.1021/ acssuschemeng.8b05735.

[15] M.N. Garcia Gonzalez, M. Levi, S. Turri, G. Griffini, Lignin nanoparticles by ultrasonication and their incorporation in waterborne polymer nanocomposites, J. Appl. Polym. Sci. 134 (2017) 1-10, https://doi.org/10.1002/app.45318.

[16] A.P. Richter, J.S. Brown, B. Bharti, A. Wang, S. Gangwal, K. Houck, E.A. Cohen Hubal, V.N. Paunov, S.D. Stoyanov, O.D. Velev, An environmentally benign antimicrobial nanoparticle based on a silver-infused lignin core, Nat. Nanotechnol. 10 (2015) 817-823, https://doi.org/10.1038/nnano.2015.141.

[17] Q. Lu, M. Zhu, Y. Zu, W. Liu, L. Yang, Y. Zhang, X. Zhao, X. Zhang, X. Zhang, W. Li, Comparative antioxidant activity of nanoscale lignin prepared by a supercritical antisolvent (SAS) process with non-nanoscale lignin, Food Chem. 135 (2012) 63-67, https://doi.org/10.1016/j.foodchem.2012.04.070.

[18] S.R. Yearla, K. Padmasree, Preparation and characterisation of lignin nanoparticles: evaluation of their potential as antioxidants and UV protectants, J. Exp. Nanosci. 11 (2016) 289-302, https://doi.org/10.1080/17458080.2015.1055842.

[19] D. Xiao, W. Ding, J. Zhang, Y. Ge, Z. Wu, Z. Li, Fabrication of a versatile lignin-based nano-trap for heavy metal ion capture and bacterial inhibition, Chem. Eng. J. 358 (2019) 310-320, https://doi.org/10.1016/j.cej.2018.10.037.

[20] I.A. Gilca, V.I. Popa, C. Crestini, Obtaining lignin nanoparticles by sonication, Ultrason. Sonochem. 23 (2015) 369-375, https://doi.org/10.1016/j.ultsonch.2014 08.021.

[21] M. Lievonen, J. Valle Delgado, M.-L. Mattinen, E.-L. Hult, K. Lintinen, M. Kostiainen, A. Paananen, G. Szilvay, H. Setälä, M. Österberg, Simple process for lignin nanoparticle preparation, Green Chem. 18 (2016) 1416-1422, https://doi.org/10.1039/ C5GC01436K.

[22] L. Chen, X. Zhou, Y. Shi, B. Gao, J. Wu, T.B. Kirk, J. Xu, W. Xue, Green synthesis of lignin nanoparticle in aqueous hydrotropic solution toward broadening the window for its processing and application, Chem. Eng. J. 346 (2018) 217-225, https://doi. $\operatorname{org} / 10.1016 /$ j.cej.2018.04.020.

[23] P.K. Mishra, A. Ekielski, A simple method to synthesize lignin nanoparticles, Colloids Interfaces 3 (2019) 1-6, https://doi.org/10.3390/colloids3020052.

[24] A.A. Myint, H.W. Lee, B. Seo, W.S. Son, J. Yoon, T.J. Yoon, H.J. Park, J. Yu, J. Yoon, Y.W. Lee, One pot synthesis of environmentally friendly lignin nanoparticles with compressed liquid carbon dioxide as an antisolvent, Green Chem. 18 (2016) 2129-2146, https://doi.org/10.1039/c5gc02398j.

[25] A.P. Richter, B. Bharti, H.B. Armstrong, J.S. Brown, D. Plemmons, V.N. Paunov, S.D. Stoyanov, O.D. Velev, Synthesis and characterization of biodegradable lignin nanoparticles with tunable surface properties, Langmuir 32 (2016) 6468-6477, https:// doi.org/10.1021/acs.langmuir.6b01088.

[26] Z--H. Liu, N. Hao, S. Shinde, Y. Pu, X. Kang, AJ. Ragauskas, J.S. Yuan, Defining lignin nanoparticle properties through tailored lignin reactivity by sequential organosolv fragmentation approach (SOFA), Green Chem. 21 (2019) 245-260, https://doi.org/ 10.1039/C8GC03290D.

[27] L. Matsakas, M. Gerber, L. Yu, U. Rova, P. Christakopoulos, Preparation of low carbon impact lignin nanoparticles with controllable size by using different strategies for particles recovery, Ind. Crop. Prod. 147 (2020), 112243, https://doi.org/10.1016/j. indcrop.2020.112243.

[28] L. Matsakas, A. Karnaouri, A. Cwirzen, U. Rova, P. Christakopoulos, Formation of lignin nanoparticles by combining organosolv pretreatment of birch biomass and homogenization processes, Molecules 23 (2018) 1822, https://doi.org/10.3390/ molecules23071822.

[29] European Commission, Recommendations: commission recommendation of 18 October 2011 on the definition of nanomaterial (text with EEA relevance) (2011/696/ EU), Off. J. Eur. Union L275 (2011) 38-40.

[30] FDA, Guidance for industry considering whether an FDA-regulated product involves the application of nanotechnology, Biotechnol. Law Rep. 30 (2011) 613-616, https://doi.org/10.1089/blr.2011.9814.

[31] M. Michelin, S. Liebentritt, A.A. Vicente, J.A. Teixeira, Lignin from an integrated process consisting of liquid hot water and ethanol organosolv: physicochemical and antioxidant properties, Int. J. Biol. Macromol. 120 (2018) 159-169, https://doi.org/10 1016/j.ijbiomac.2018.08.046.

[32] H. Fessi, F. Puisieux, J.P. Devissaguet, N. Ammoury, S. Benita, Nanocapsule formation by interfacial polymer deposition following solvent displacement, Int. J. Pharm. 55 (1989) R1-R4, https://doi.org/10.1016/0378-5173(89)90281-0.

[33] Malvern, Zetasizer Nano Series User Manual, MAN0317 Issue 2.1, 2013.

[34] R. Re, N. Pellegrini, A. Proteggente, A. Pannala, M. Yang, C. Rice-Evans, Antioxidant activity applying an improved ABTS radical cation decolorization assay, Free Radic. Biol. Med. 26 (1999) 1231-1237, https://doi.org/10.1016/S0891-5849(98)00315-3.

[35] A. Garrido-Maestu, P. Fuciños, S. Azinheiro, J. Carvalho, M. Prado, Systematic loopmediated isothermal amplification assays for rapid detection and characterization of Salmonella spp., Enteritidis and Typhimurium in food samples, Food Control 80 (2017) 297-306, https://doi.org/10.1016/j.foodcont.2017.05.011.

[36] M.E. Kellett, P. Greenspan, R.B. Pegg, Modification of the cellular antioxidant activity (CAA) assay to study phenolic antioxidants in a Caco-2 cell line, Food Chem. 244 (2018) 359-363, https://doi.org/10.1016/j.foodchem.2017.10.035.

[37] M. Marimoutou, L. Fanny, J. Smadja, C. Lefebvre d'Hellencourt, M.-P. Gonthier, C. Robert-Da Silva, Antioxidant polyphenol-rich extracts from the medicinal plants Antirhea borbonica, Doratoxylon apetalum and Gouania mauritiana protect 3T3L1 preadipocytes against $\mathrm{H} 2 \mathrm{O} 2$, TNF $\alpha$ and LPS inflammatory mediators by 
regulating the expression of superoxide dismut, J. Inflamm. (Lond.) 12 (2015) 10 , https://doi.org/10.1186/s12950-015-0055-6.

[38] P.X. Chen, H. Zhang, M.F. Marcone, K.P. Pauls, R. Liu, Y. Tang, B. Zhang, J.B. Renaud, R. Tsao, Anti-inflammatory effects of phenolic-rich cranberry bean (Phaseolus vulgaris L.) extracts and enhanced cellular antioxidant enzyme activities in Caco-2 cells, J. Funct. Foods 38 (2017) 675-685, https://doi.org/10.1016/j.jff.2016.12.027.

[39] A. Piccolomini, M.M. Iskandar, L.C. Lands, S. Kubow, High hydrostatic pressure pretreatment of whey proteins enhances whey protein hydrolysate inhibition of oxidative stress and IL-8 secretion in intestinal epithelial cells, Food Nutr. Res. 56 (2012), 17549, https://doi.org/10.3402/fnr.v56i0.17549.

[40] U. Nobbmann, A. Morfesis, Light scattering and nanoparticles, Mater. Today 12 (2009) 52-54, https://doi.org/10.1016/S1369-7021(09)70164-6.

[41] F. Xiong, Y. Han, S. Wang, G. Li, T. Qin, Y. Chen, F. Chu, Preparation and formation mechanism of size-controlled lignin nanospheres by self-assembly, Ind. Crop. Prod. 100 (2017) 146-152, https://doi.org/10.1016/j.indcrop.2017.02.025.

[42] M. Silva, D. Cocenza, R. Grillo, N. de Melo, P. Tonello, L. Oliveira, D. Cassimiro, A. Rosa, L. Fraceto, Paraquat-loaded alginate/chitosan nanoparticles: preparation, characterization and soil sorption studies, J. Hazard. Mater. 190 (2011) 366-374, https://doi. org/10.1016/j.jhazmat.2011.03.057.

[43] X. Zhang, M. Yang, Q. Yuan, G. Cheng, Controlled preparation of corncob lignin nanoparticles and their size-dependent antioxidant properties: toward high value utilization of lignin, ACS Sustain. Chem. Eng. 7 (2019) 17166-17174, https://doi.org/ 10.1021/acssuschemeng.9b03535.

[44] O.U. Rahman, S. Shi, J. Ding, D. Wang, S. Ahmad, H. Yu, Lignin nanoparticles: synthesis, characterization and corrosion protection performance, New J. Chem. 42 (2018) 3415-3425, https://doi.org/10.1039/c7nj04103a.

[45] O. Faix, Classification of lignins from different botanical origins by FT-IR spectroscopy, Holzforschung 45 (1991) 21-28, https://doi.org/10.1515/hfsg.1991.45.s1.21.

[46] M.N.M. Ibrahim, S.B. Chuah, W.D. Wan Rosli, Characterization of lignin precipitated from the soda black liquor of oil palm empty fruit bunch fibers by various mineral acids, Asian J. Sci. Technol. Dev. 21 (2004) 57-67, https://doi.org/10.29037/ajstd.92.

[47] F. Monteil-Rivera, M. Phuong, M. Ye, A. Halasz, J. Hawari, Isolation and characterization of herbaceous lignins for applications in biomaterials, Ind. Crop. Prod. 41 (2013) 356-364, https://doi.org/10.1016/j.indcrop.2012.04.049.

[48] Y.-Y. Bai, L.-P. Xiao, Z.-J. Shi, R.-C. Sun, Structural variation of bamboo lignin before and after ethanol organosolv pretreatment, Int. J. Mol. Sci. 14 (2013) 21394-21413, https://doi.org/10.3390/ijms141121394.

[49] W. Yang, J.M. Kenny, D. Puglia, Structure and properties of biodegradable wheat gluten bionanocomposites containing lignin nanoparticles, Ind. Crop. Prod. 74 (2015) 348-356, https://doi.org/10.1016/j.indcrop.2015.05.032.

[50] S.J. Lee, H.J. Kim, E.J. Cho, Y. Song, H.-J. Bae, Isolation and characterization of lignin from the oak wood bioethanol production residue for adhesives, Int. J. Biol. Macromol. 72 (2015) 1056-1062, https://doi.org/10.1016/j.ijbiomac.2014.10.020.

[51] B. Hansen, P. Kusch, M. Schulze, B. Kamm, Qualitative and quantitative analysis of lignin produced from beech wood by different conditions of the organosolv process, J. Polym. Environ. 24 (2016) 85-97, https://doi.org/10.1007/s10924-015-0746-3.

[52] M.A. Khan, S.M. Ashraf, V.P. Malhotra, Eucalyptus bark lignin substituted phenol formaldehyde adhesives: a study on optimization of reaction parameters and characterization, J. Appl. Polym. Sci. 92 (2004) 3514-3523, https://doi.org/10.1002/app. 20374.

[53] W.E. Collier, T.P. Schultz, V.F. Kalasinsky, Infrared study of lignin: reexamination of aryl-alkyl ether C-O stretching peak assignments, Holzforschung. 46 (1992) 523-528http://inis.iaea.org/search/search.aspx?orig_q=RN:46076069.

[54] N. Shukry, S. Fadel, F. Agblevor, S. El-Kalyoubi, Some physical properties of acetosolv lignins from bagasse, J. Appl. Polym. Sci. 109 (2008) 434-444, https://doi.org/10. 1002/app.28059.

[55] J.C. Domínguez, M. Oliet, M.V. Alonso, M.A. Gilarranz, F. Rodríguez, Thermal stability and pyrolysis kinetics of organosolv lignins obtained from Eucalyptus globulus, Ind. Crop. Prod. 27 (2008) 150-156, https://doi.org/10.1016/j.indcrop.2007.07.006.

[56] M. Balat, Mechanisms of thermochemical biomass conversion processes. Part 1: reactions of pyrolysis, energy sources, part A recover, Util. Environ. Eff. 30 (2008) 620-635, https://doi.org/10.1080/15567030600817258.

[57] E. Jakab, O. Faix, F. Till, Thermal decomposition of milled wood lignins studied by thermogravimetry/mass spectrometry, J. Anal. Appl. Pyrolysis 40-41 (1997) 171-186, https://doi.org/10.1016/S0165-2370(97)00046-6.

[58] A. Tejado, C. Peña, J. Labidi, J.M. Echeverria, I. Mondragon, Physico-chemical characterization of lignins from different sources for use in phenol-formaldehyde resin synthesis, Bioresour. Technol. 98 (2007) 1655-1663, https://doi.org/10.1016/j. biortech.2006.05.042.

[59] J.-L. Wen, S.-L. Sun, B.-L. Xue, R.-C. Sun, Quantitative structures and thermal properties of birch lignins after ionic liquid pretreatment, J. Agric. Food Chem. 61 (2013) 635-645, https://doi.org/10.1021/jf3051939.

[60] A.K. Gupta, S. Mohanty, S.K. Nayak, Synthesis, characterization and application of lignin nanoparticles (LNPs), Mater. Focus. 3 (2014) 444-454, https://doi.org/10.1166/ mat.2014.1217.

[61] R.M. Overney, C. Buenviaje, R. Luginbühl, F. Dinelli, Glass and structural transitions measured at polymer surfaces on the nanoscale, J. Therm. Anal. Calorim. 59 (2000) 205-225, https://doi.org/10.1023/A:1010196214867.

[62] F. Lu, L. Chu, R. Gau, Free radical-scavenging properties of lignin, Nutr. Cancer 30 (1998) 31-38, https://doi.org/10.1080/01635589809514637.

[63] T. Dizhbite, G. Telysheva, V. Jurkjane, U. Viesturs, Characterization of the radical scavenging activity of lignins - natural antioxidants, Bioresour. Technol. 95 (2004) 309-317, https://doi.org/10.1016/j.biortech.2004.02.024.

[64] L. An, G. Wang, H. Jia, C. Liu, W. Sui, C. Si, Fractionation of enzymatic hydrolysis lignin by sequential extraction for enhancing antioxidant performance, Int. J. Biol. Macromol. 99 (2017) 674-681, https://doi.org/10.1016/j.ijbiomac.2017.03.015.

[65] G. Cazacu, A.-M. Căpraru, V. Popa, Advances concerning lignin utilization in new materials, Adv. Struct. Mater. 2013, pp. 255-312, https://doi.org/10.1007/978-3-64220940-6 8.

[66] J.L. Espinoza-acosta, P.I. Torres-chávez, B. Ramírez-wong, Antioxidant, antimicrobial, and antimutagenic properties of technical lignins and their applications, BioResources. 11 (2016) 5452-5481.

[67] W. Yang, E. Fortunati, F. Dominici, G. Giovanale, A. Mazzaglia, G.M. Balestra, J.M. Kenny, D. Puglia, Synergic effect of cellulose and lignin nanostructures in PLA based systems for food antibacterial packaging, Eur. Polym. J. 79 (2016) 1-12, https://doi.org/10.1016/j.eurpolymj.2016.04.003.

[68] W. Yang, J.S. Owczarek, E. Fortunati, M. Kozanecki, A. Mazzaglia, G.M. Balestra, J.M Kenny, L. Torre, D. Puglia, Antioxidant and antibacterial lignin nanoparticles in polyvinyl alcohol/chitosan films for active packaging, Ind. Crop. Prod. 94 (2016) 800-811, https://doi.org/10.1016/j.indcrop.2016.09.061.

[69] W. Yang, E. Fortunati, F. Bertoglio, J.S. Owczarek, G. Bruni, M. Kozanecki, J.M. Kenny, L. Torre, L. Visai, D. Puglia, Polyvinyl alcohol/chitosan hydrogels with enhanced antioxidant and antibacterial properties induced by lignin nanoparticles, Carbohydr. Polym. 181 (2018) 275-284, https://doi.org/10.1016/j.carbpol.2017.10.084.

[70] L. Wang, C. Hu, L. Shao, The antimicrobial activity of nanoparticles: present situation and prospects for the future, Int. J. Nanomedicine 12 (2017) 1227-1249, https://doi. org/10.2147/IJN.S121956.

[71] M. Arakha, S. Pal, D. Samantarrai, T.K. Panigrahi, B.C. Mallick, K. Pramanik, B. Mallick, S. Jha, Antimicrobial activity of iron oxide nanoparticle upon modulation of nanoparticle-bacteria interface, Sci. Rep. 5 (2015), 14813, https://doi.org/10.1038/ srep14813.

[72] M.S. Barber, V.S. McConnell, B.S. DeCaux, Antimicrobial intermediates of the general phenylpropanoid and lignin specific pathways, Phytochemistry 54 (2000) 53-56, https://doi.org/10.1016/S0031-9422(00)00038-8.

[73] A. Verma, F. Stellacci, Effect of surface properties on nanoparticle-cell interactions, Small 6 (2010) 12-21, https://doi.org/10.1002/smll.200901158.

[74] A. Albanese, P.S. Tang, W.C.W. Chan, The effect of nanoparticle size, shape, and surface chemistry on biological systems, Annu. Rev. Biomed. Eng. 14 (2012) 1-16, https://doi.org/10.1146/annurev-bioeng-071811-150124.

[75] ISO, ISO 1993-5: Biological Evaluation of Medical Devices - Part 5: Tests for In Vitro Cytotoxicity, 2009 1-34.

[76] H.L. Karlsson, J. Gustafsson, P. Cronholm, L. Möller, Size-dependent toxicity of metal oxide particles-a comparison between nano- and micrometer size, Toxicol. Lett. 188 (2009) 112-118, https://doi.org/10.1016/j.toxlet.2009.03.014.

[77] H.A. Santos, J. Riikonen, J. Salonen, E. Mäkilä, T. Heikkilä, T. Laaksonen, L. Peltonen, V.-P. Lehto, J. Hirvonen, In vitro cytotoxicity of porous silicon microparticles: effect of the particle concentration, surface chemistry and size, Acta Biomater. 6 (2010) 2721-2731, https://doi.org/10.1016/j.actbio.2009.12.043.

[78] A. Manke, L. Wang, Y. Rojanasakul, Mechanisms of nanoparticle-induced oxidative stress and toxicity, Biomed. Res. Int. 2013 (2013), 942916, https://doi.org/10. 1155/2013/942916.

[79] P. Khanna, C. Ong, B.H. Bay, G.H. Baeg, Nanotoxicity: an interplay of oxidative stress, inflammation and cell death, Nanomater. (Basel, Switzerland) 5 (2015) 1163-1180, https://doi.org/10.3390/nano5031163. 